\title{
VOC Transport in Vented Drums Containing Simulated Waste Sludge
}

\author{
Kevin J. Liekhus \\ Garold L. Gresham \\ Cathy Rae \\ Mike J. Connolly
}

Published February 1994
Idaho National Engineering Laboratory
EG\&G Idaho, Inc.
Idaho Falls, Idaho 83415

\section{Prepared for the}

U.S. Department of Energy, Assistant Secretary for Environmental Restoration and Waste Management Under DOE Idaho Operations Office Contract DE-AC07-76ID01570

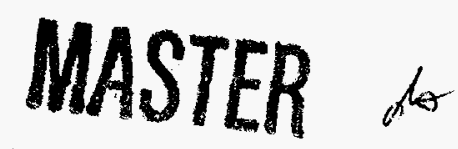




\section{DISCLAIMER}

This report was prepared as an account of work sponsored by an agency of the United States Government. Neither the United States Government nor any agency thereof, nor any of their employees, make any warranty, express or implied, or assumes any legal liability or responsibility for the accuracy, completeness, or usefulness of any information, apparatus, product, or process disclosed, or represents that its use would not infringe privately owned rights. Reference herein to any specific commercial product, process, or service by trade name, trademark, manufacturer, or otherwise does not necessarily constitute or imply its endorsement, recommendation, or favoring by the United States Government or any agency thereof. The views and opinions of authors expressed herein do not necessar. ily state or reflect those of the United States Government or any agency thereof. 


\section{DISCLAIMER}

Portions of this document may be illegible electronic image products. Images are produced from the best available original document. 


\begin{abstract}
A model is developed to estimate the volatile organic compound (VOC) concentration in the headspace of the innermost layer of confinement in a lab-scale vented waste drum containing simulated waste sludge. The VOC transport model estimates the concentration using the measured VOC concentration beneath the drum lid and model parameters defined or estimated from process knowledge of drum contents and waste drum configuration. Model parameters include the VOC diffusion characteristic across the filter vent, VOC diffusivity in air, size of opening in the drum liner lid, the type and number of layers of polymer bags surrounding the waste, VOC permeability across the polymer, and the permeable surface area of the polymer bags. Comparison of model and experimental results indicates that the model can accurately estimate VOC concentration in the headspace of the innermost layer of confinement. The model may be useful in estimating the VOC concentration in actual waste drums.
\end{abstract}




\section{EXECUTIVE SUMMARY}

A test program is underway at the Idaho National Engineering Laboratory to determine if the drum headspace volatile organic compound (VOC) concentration is representative of the VOC concentration in the entire drum void space and demonstrate that the VOC concentration in the void space of each layer of confinement can be estimated using a model incorporating theoretical diffusive and permeative transport principles and limited waste drum sampling data. The test program consists of three stages. In the first stage, a model was developed to demonstrate that the unsteady-state VOC transport from vented lab-scale waste drums could be estimated based on measured or estimated transport parameters and prior knowledge of the initial VOC concentration inside the drum. In the second stage, a transport model was developed to estimate VOC concentration in the headspace of the innermost layer of confinement in lab-scale vented waste drums containing simulated waste sludge with a high VOC content. In the final stage, the model developed in the second stage will be used to estimate VOC concentrations in actual waste drums and determine if the drum headspace concentration is representative of the concentration throughout the drum. This report describes the results of the second stage of the test program.

A transport model was developed to estimate the VOC concentration throughout a lab-scale vented waste drum containing a simulated waste sludge based on the knowledge of drum headspace VOC concentration and waste drum configuration. Waste drum configuration describes the type of filter vent in the drum lid; the dimensions of the opening in the drum liner lid; and the type, number, and thickness of large and small polymer bags surrounding the waste. The model consisted of a series of material balance equations describing steady-state VOC transport across each layer of confinement. It was assumed that permeation is the primary transport mechanism across the polymer bags and diffusion is the primary transport mechanism across the drum liner headspace and drum headspace. In addition, it was assumed that an equilibrium exists between the vapor phase and any VOC-containing source in the innermost layer of confinement.

Two experiments were performed to measure the VOC concentration in lab-scale vented waste drums containing simulated waste sludge. In Trial 1 , a simulated waste sludge containing methylene chloride, 1,1,1-trichloroethane (TCA), 1,1,2-trichloro-1,2,2-trifluoroethane (Freon-113), carbon tetrachloride, and trichloroethylene (TCE) was placed inside a large polyethylene bag inside the waste drum. In Trial 2, a simulated waste sludge containing methanol, cyclohexane, TCA, toluene, and p-xylene was placed inside two small polyethylene bags located inside a large polyethylene bag. Two drums and drum liners were vented at the beginning of the Trial 2 test period and two drums were vented 31 days after the trial began.

Experimental results were expressed as a ratio between drum headspace VOC concentration and the VOC concentration inside the innermost polyethylene bag. The concentration ratio was calculated to minimize daily fluctuations that affected all measurements on a given day. The daily ratio also demonstrated when the transport rates were nearly equivalent. An average concentration ratio was calculated for all waste drums in a given trial. Most concentration ratios approached a constant value indicative of nearly equal transport rates from the innermost layer of confinement and the drum headspace. During Trial 1, the time required for the concentration ratio to reach a constant value varied between 10 to 50 days, depending on the VOC. During 
Trial 2, the concentration ratio for toluene and p-xylene did not reach a constant value after 86 days. The time necessary to reach a near-constant value is a function of the filter vent diffusion characteristic, total number of layers of confinement, and the VOC vapor pressure. Model results for all VOCs, excluding toluene and p-xylene, were within a $95 \%$ confidence range of the experimental data.

Model equations were used to determine the effect of model parameters on the estimated concentration difference across a transport boundary, such as the liner lid or polymer bag. The VOC concentration difference across the drum liner will decrease with a larger cross-sectional area of the opening in the liner lid or a smaller VOC diffusion characteristic across the filter vent. The concentration difference across the polymer bag will decrease with a larger permeable surface area or a smaller polymer bag thickness. These variables are a function of the waste packaging configuration. In addition, a smaller VOC diffusion characteristic across the filter vent or a larger VOC permeability across the polymer bag will also decrease the concentration difference. All VOC permeabilities used in model calculations were measured at vapor concentrations less than measured during the lab-scale waste drum experiments. Vapor permeability coefficients generally increase with increasing vapor concentration. Depending on the waste drum configuration, the use of a larger permeability value could significantly reduce the estimated concentration difference across a polymer bag. Using a VOC permeability that was measured across an identical or similar polymer at a lower vapor concentration than exists under actual conditions will result in a conservative estimate of the concentration difference across the bag.

The VOC transport model has been demonstrated to accurately estimate the headspace concentration inside the innermost bag in a lab-scale vented waste drum containing simulated waste sludge. Model estimates of the inner bag concentrations are dependent on knowledge of drum headspace concentration at a given time. The model does not characterize the VOC transport rate as a function of time. In future experiments, the same model will be used to estimate the VOC concentration within actual waste drums at a given time. 


\section{CONTENTS}

ABSTRACT $\ldots \ldots \ldots \ldots \ldots \ldots \ldots \ldots \ldots \ldots \ldots \ldots \ldots \ldots \ldots \ldots \ldots \ldots \ldots \ldots$

EXECUTIVE SUMMARY $\ldots \ldots \ldots \ldots \ldots \ldots \ldots \ldots \ldots \ldots \ldots \ldots \ldots \ldots$

ACRONYMS $\ldots \ldots \ldots \ldots \ldots \ldots \ldots \ldots \ldots \ldots \ldots \ldots \ldots \ldots \ldots \ldots \ldots \ldots \ldots \ldots$

1. INTRODUCTION $\ldots \ldots \ldots \ldots \ldots \ldots \ldots \ldots \ldots \ldots \ldots \ldots \ldots \ldots \ldots \ldots$

2. VOC TRANSPORT MODEL $\ldots \ldots \ldots \ldots \ldots \ldots \ldots \ldots \ldots \ldots \ldots \ldots \ldots \ldots \ldots$

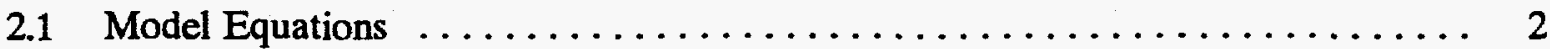

2.2 Model Assumptions $\ldots \ldots \ldots \ldots \ldots \ldots \ldots \ldots \ldots \ldots \ldots \ldots \ldots \ldots$

3. VOC TRANSPORT EXPERIMENTS $\ldots \ldots \ldots \ldots \ldots \ldots \ldots \ldots \ldots \ldots \ldots \ldots$

3.1 Experimental Design $\ldots \ldots \ldots \ldots \ldots \ldots \ldots \ldots \ldots \ldots \ldots \ldots \ldots \ldots \ldots \ldots$

3.2 Automated Experimental Configuration $\ldots \ldots \ldots \ldots \ldots \ldots \ldots \ldots$

3.3 Experimental Procedures $\ldots \ldots \ldots \ldots \ldots \ldots \ldots \ldots \ldots \ldots \ldots \ldots \ldots$

3.4 Quality Control $\ldots \ldots \ldots \ldots \ldots \ldots \ldots \ldots \ldots \ldots \ldots \ldots \ldots \ldots \ldots \ldots$

3.4.1 Quality Control Samples $\ldots \ldots \ldots \ldots \ldots \ldots \ldots \ldots \ldots \ldots$

3.4.2 Additional Quality Checks ...................... 9

4. EXPERIMENTAL AND MODEL RESULTS $\ldots \ldots \ldots \ldots \ldots \ldots \ldots \ldots \ldots \ldots \ldots$

4.1 VOC Transport Experiments $\ldots \ldots \ldots \ldots \ldots \ldots \ldots \ldots \ldots \ldots \ldots \ldots \ldots$

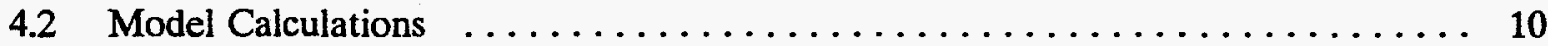

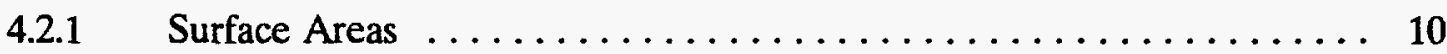

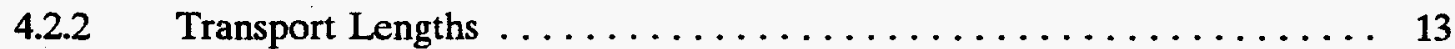

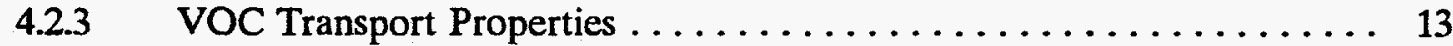

4.2.4 Temperature and Pressure $\ldots \ldots \ldots \ldots \ldots \ldots \ldots \ldots \ldots \ldots \ldots$

4.3 Model Results $\ldots \ldots \ldots \ldots \ldots \ldots \ldots \ldots \ldots \ldots \ldots \ldots \ldots \ldots \ldots \ldots \ldots$

4.4 Effect of Parameter Values on Model Results $\ldots \ldots \ldots \ldots \ldots \ldots \ldots \ldots \ldots$

4.4.1 VOC Diffusion $\ldots \ldots \ldots \ldots \ldots \ldots \ldots \ldots \ldots \ldots \ldots \ldots$

4.4.2 VOC Permeation $\ldots \ldots \ldots \ldots \ldots \ldots \ldots \ldots \ldots \ldots \ldots \ldots$ 


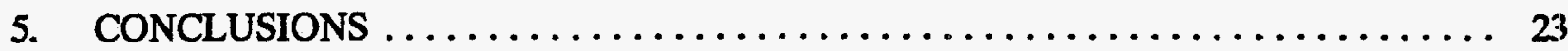

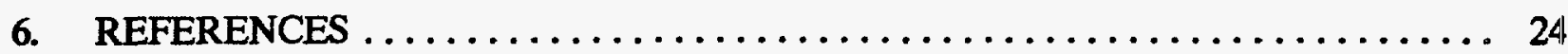

Appendix A-Measured VOC Concentrations in Lab-scale Waste Drums . . . . . . . . . . A-1

Appendix B-Computer Program to Estimate VOC Concentration Ratio

in Vented Waste Drums Containing VOC Source $\ldots \ldots \ldots \ldots \ldots \ldots \ldots \ldots . \ldots .1$

\section{FIGURES}

1. General schematic of lab-scale waste drum $\ldots \ldots \ldots \ldots \ldots \ldots \ldots \ldots \ldots \ldots$

2. Automated VOC transport experimental configuration $\ldots \ldots \ldots \ldots \ldots \ldots \ldots$

3. The measured TCA concentration within drum headspace and large bag headspace of lab-scale waste drums during Trial $\ldots \ldots \ldots \ldots \ldots \ldots \ldots \ldots \ldots \ldots \ldots$

4. The measure TCA concentration within drum headspace and small bag headspace of lab-scale waste drums during Trial $2 \ldots \ldots \ldots \ldots \ldots \ldots \ldots \ldots \ldots \ldots \ldots \ldots \ldots$

5. Daily average drum headspace-to-large bag headspace VOC concentration ratio and model predictions during Trial $1 \ldots \ldots \ldots \ldots \ldots \ldots \ldots \ldots \ldots \ldots \ldots \ldots$

6. Daily average drum headspace-to-small bag headspace VOC concentration ratio and model predictions during Trial $2 \ldots \ldots \ldots \ldots \ldots \ldots \ldots \ldots \ldots \ldots \ldots$

7. Predicted VOC concentration ratios in Trial 1 using a VOC diffusion characteristics defined by the mean value, $D^{*}$, and the standard deviation about the mean, $\sigma \ldots \ldots$

8. Predicted VOC concentration ratios in Trial 2 using a VOC diffusion characteristics defined by the mean value, $D^{*}$, and the standard deviation about the mean, $\sigma \ldots \ldots$

\section{TABLES}

1. Experimental design for simulated waste drum VOC transport experiments $\ldots \ldots \ldots$

2. Trial 1 sludge mixture $\ldots \ldots \ldots \ldots \ldots \ldots \ldots \ldots \ldots \ldots \ldots \ldots \ldots \ldots \ldots \ldots$

3. Trial 2 sludge mixture $\ldots \ldots \ldots \ldots \ldots \ldots \ldots \ldots \ldots \ldots \ldots \ldots \ldots \ldots \ldots$

4. Vapor permeability coefficient across a polyethylene bag at $25^{\circ} \mathrm{C}$ at a specific VOC

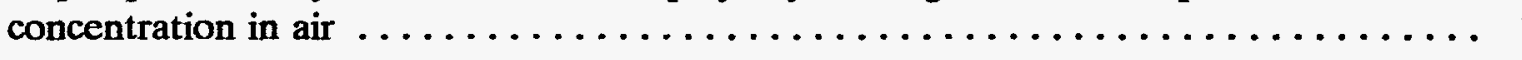


5. Comparison of VOC vapor pressure and approximate average time when near-constant drum-headspace-to-large-bag VOC concentration ratio was

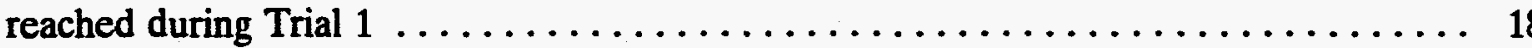

6. Comparison of VOC vapor pressure and approximate average time when near-constant drum-headspace-to-small-bag VOC concentration ratio was

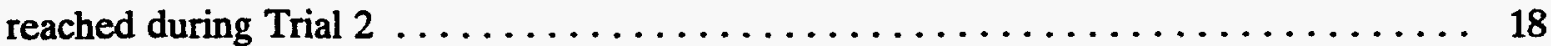

A-1. Measured VOC concentration (ppmv) in Drum 2 headspaces during Trial $1 \ldots \ldots$. . A-3

A-2. Measured VOC concentration (ppmv) in Drum 3 headspaces during Trial $1 \ldots \ldots$. . A-4

A-3. Measured VOC concentration (ppmv) in Drum 4 headspaces during Trial $1 \ldots \ldots$... A-5

A-4. Measured VOC concentration (ppmv) in Drum 1 headspaces during Trial $2 \ldots \ldots$ A-6

A-5. Measured VOC concentration (ppmv) in Drum 2 headspaces during Trial $2 \ldots \ldots$ A-7

A-6. Measured VOC concentration (ppmv) in Drum 3 headspaces during Trial $2 \ldots \ldots$. . A-8

A-7. Measured VOC concentration (ppmv) in Drum 4 headspaces during Trial $2 \ldots \ldots$... A-9 


\title{
ACRONYMS
}

\author{
DOE U.S. Department of Energy \\ EPA U.S. Environmental Protection Agency \\ STP standard temperature and pressure \\ TCA 1,1,1-trichloroethane \\ TCE trichloroethylene \\ VOC volatile organic compound \\ WIPP Waste Isolation Pilot Plant
}




\section{VOC Transport in Vented Drums Containing Simulated Waste Sludge}

\section{INTRODUCTION}

Pretest waste characterization of waste drums for the bin-scale tests at the Waste Isolation Pilot Plant (WIPP) includes sampling for volatile organic compounds (VOCs) from three areas within drums (drum headspace, the 55-gal polymer bag headspace, and the innermost layer of confinement headspace) of transuranic waste. ${ }^{1}$ The Department of Energy (DOE) must demonstrate to the Environmental Protection Agency (EPA) that a drum headspace sample is representative of the VOCs within the entire void space of the waste container in order to demonstrate compliance in the future when drums could be directly emplaced in the WIPP. The WIPP conditional no-migration determination specifies that the EPA expects that all layers of confinement in a container will have to be sampled until DOE can demonstrate, based on data collected, that sampling of all layers is either unnecessary or can be safely reduced.

A test program is underway at the Idaho National Engineering Laboratory to determine if the drum headspace VOC concentration is representative of the concentration in the entire drum void space and demonstrate that the VOC concentration in the void space of each layer of confinement can be estimated using a model incorporating theoretical diffusive and permeative transport principles and limited waste drum sampling data. The test program consists of three stages. In the first stage, a model was developed to demonstrate that the unsteady-state VOC transport from vented lab-scale waste drums could be calculated based on measured or estimated transport parameters and prior knowledge of the initial VOC concentration inside the drum. ${ }^{2}$ The second stage involves development of a model to estimate VOC concentration in the headspace of the innermost layer of confinement in a lab-scale vented waste drum containing simulated waste sludge with a high VOC content. The final stage will use the model developed in the second stage to estimate VOC concentrations in actual waste drums. In each stage, a comparison of model estimates and experimentally measured VOC concentrations in lab-scale or actual waste drums were or will be made to validate model accuracy. A model capable of characterizing the VOC concentration in an actual waste drum will be useful in defining drum headspace representativeness and may more quickly eliminate the need to sample all inner layers of confinement which will result in lower worker radiation exposure, decreased bin loading times, and significant cost savings over the life of the WIPP test and operational phases.

This report describes model development and VOC transport experiments in lab-scale vented waste drums containing simulated waste sludges. Development of the VOC transport model is presented in Section 2. Section 3 contains a description of the experimental design for the VOC transport experiments and permeability measurements. The experimental and model results are presented and discussed in Section 4. The report conclusions are summarized in Section 5. 


\section{VOC TRANSPORT MODEL}

A transport model was developed to estimate the VOC concentration in void volumes within a vented drum containing a waste that is a source of VOC emissions. Model parameters are defined from knowledge of drum headspace VOC concentration and waste drum configuration. A general schematic of a lab-scale waste drum configuration used in VOC transport experiments is shown in Figure 1. The waste drum configuration includes the type of filter vent in the drum lid; the dimensions of the opening the drum liner lid; and the type, number, and thickness of large and small polymer bags surrounding the waste. The model consists of a series of material balance equations describing steady-state VOC transport across each layer of confinement.

\subsection{Model Equations}

The innermost layer of confinement is referred to as the first void volume and is the headspace immediately surrounding the waste. This layer may be small bags or the large bag that lines the inside of the drum liner. The drum headspace is the final or $n^{\text {th }}$ void volume. The average VOC transport rate from the innermost layer of confinement is primarily the result of VOC permeation and is defined by the equation

$$
r_{1}=\alpha_{1}\left(c_{1}-c_{2}\right) \text {, }
$$

where

$$
\begin{array}{ll}
r_{1} & =\text { VOC transport rate from innermost void volume, mol } \mathrm{s}^{-1} \\
\alpha_{1} & =\Psi \odot \mathrm{A}_{\mathrm{p} 1} \mathrm{P} / \mathrm{x}_{\mathrm{p} 1}, \mathrm{~m}^{3} \mathrm{~s}^{-1} \\
\Psi & =\quad \begin{array}{r}
\text { ratio of gas volume at a given temperature and pressure to gas volume at } \\
\text { standard temperature and pressure (STP) }=370.95 \mathrm{~T} / \mathrm{P}
\end{array} \\
\mathrm{T} & =\text { temperature, } \mathrm{K} \\
\mathrm{P} & =\text { pressure, } \mathrm{N} \mathrm{\textrm {m } ^ { - 2 }} \\
\odot & =\text { VOC permeability coefficient, } \mathrm{m}^{3}(\mathrm{STP}) \mathrm{m} \mathrm{N}^{-1} \mathrm{~s}^{-1} \\
\mathrm{~A}_{\mathrm{p} 1} & =\text { permeable surface area of innermost layer of confinement, } \mathrm{m}^{2} \\
\mathrm{x}_{\mathrm{p} 1} & =\text { boundary thickness of innermost layer of confinement, } \mathrm{m} \\
\mathrm{c}_{\mathrm{i}} & =\text { VOC concentration within } \mathrm{i}^{\text {th }} \text { void volume, mol } \mathrm{m}^{-3} .
\end{array}
$$

In the case of $\mathbf{M}$ small bags containing all waste inside a drum, the model calculates only an average rate of VOC transport of $r_{1}$ from each bag. The total rate of VOC transport from all small bags is $\mathbf{M r}_{1}$. The VOC transport rate from the surrounding large bag into the drum liner headspace is defined, in general, as 


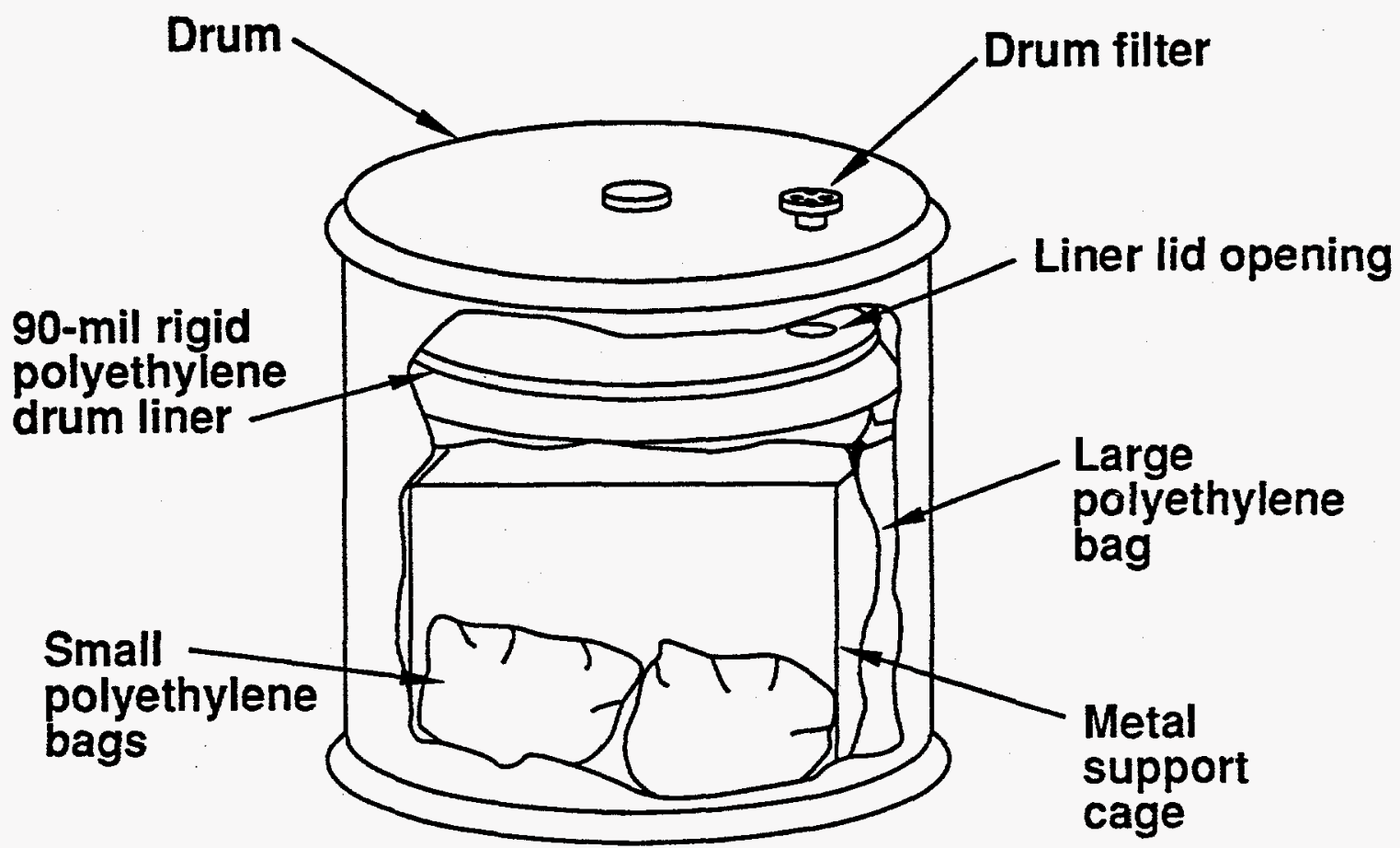

Figure 1. General schematic of lab-scale waste drum configuration.

$$
r_{n-2}=\alpha_{n-2}\left(c_{n-2}-c_{n-1}\right)
$$

which will be equivalent to Equation (1) if the large bag is the innermost layer of confinement.

The rate of VOC transport from the drum liner is defined as

$$
r_{n-1}=\beta_{n-1}\left(c_{n-1}-c_{n}\right) \text {, }
$$

where

$$
\begin{aligned}
& \beta_{\mathrm{n}-1}=\mathrm{DA}_{\mathrm{d}, \mathrm{n}-1} / \mathrm{x}_{\mathrm{d}, \mathrm{n}-1} \\
& \text { D } \quad=\quad \text { VOC-air diffusivity, } \mathrm{m}^{2} \mathrm{~s}^{-1} \\
& \mathrm{~A}_{\mathrm{d}, \mathrm{n}-1}=\text { cross-sectional area of opening in drum liner lid, } \mathrm{m}^{2} \\
& \mathbf{x}_{\mathrm{d}, \mathrm{n}-1}=\text { diffusional length across opening in drum liner lid, } \mathrm{m} \text {. }
\end{aligned}
$$

The rate of VOC transport from the drum headspace across the filter vent is defined as

$$
r_{n}=\frac{D^{*}}{c_{g}}\left(c_{n}-c_{n+1}\right)
$$


where

$$
\begin{aligned}
& D^{*}=\text { VOC filter diffusion characteristic, } \mathrm{mol} \mathrm{s}^{-1} \\
& c_{\mathrm{g}}=\text { total gas concentration in waste drum, } \mathrm{mol} \mathrm{m}^{-3} \\
& c_{\mathrm{n}+1}=\text { VOC concentration outside drum, } \mathrm{mol} \mathrm{m} .
\end{aligned}
$$

The total gas concentration can be estimated using the ideal gas law

$$
c_{8}=\frac{R T}{P}
$$

where $R$ is the gas constant.

In the case where waste is contained in $\mathbf{M}$ small polymer bags, the VOC transport rates from all void volumes are assumed to be equal or nearly equal

$$
M r_{1}=r_{2}=r_{3}=r_{4}
$$

The VOC concentrations in the other void volumes are estimated using Equations (1) through (6) and knowledge of the drum headspace VOC concentration, $c_{4}$. The values of $\alpha$ and $\beta$ are calculated based on process knowledge.

$$
\begin{aligned}
& c_{3}=c_{4}+\frac{r_{4}}{\beta_{3}}, \\
& c_{2}=c_{3}+\frac{r_{4}}{\alpha_{2}}, \\
& c_{1}=c_{2}+\frac{\left(r_{4} / M\right)}{\alpha_{1}} .
\end{aligned}
$$

\subsection{Model Assumptions}

The following assumptions were made in order to estimate the relationship between the VOC concentration measured in the drum headspace and the VOC concentrations in the other layers of confinement:

1. All VOC transport rates across the layers of confinement are at steady state. 
2. The primary mechanisms for VOC transport are permeation across the polymer bags and diffusion across the drum liner and drum headspaces.

3. The VOC concentration throughout each void volume is uniform and is zero outside the waste drum.

4. The VOC concentrations in each small bag are equal.

5. All VOC properties and other model parameters remain constant.

6. An equilibrium exists between the vapor phase and the VOC source in the innermost layer of confinement. 


\section{VOC TRANSPORT EXPERIMENTS}

\subsection{Experimental Design}

Lab-scale VOC transport experiments were developed to measure the VOC concentration in a vented waste drum containing simulated waste sludge with high VOC content. Two experimental trials were performed to demonstrate the influence of the type of VOC and the number of layers of confinement on VOC transport from vented drums. In the first trial, a simulated waste sludge containing methylene chloride, 1,1,1-trichloroethane (TCA), 1,1,2trichloro-1,2,2-trifluoroethane (Freon-113), carbon tetrachloride, and trichloroethylene (TCE) was placed inside a large polyethylene bag in the waste drum. In the second trial, a simulated waste sludge containing methanol, cyclohexane, TCA, toluene, and p-xylene was placed inside two smaller polyethylene bags that were placed inside a large polyethylene bag. In addition, two of the drums and drum liners were vented at the beginning of the Trial 2 test period and the other two drums were not vented until 31 days after the trial began to determine if there would be a difference between VOC concentrations in the headspaces of the vented and unvented drums containing similar waste matrices. The experimental design is summarized in Table 1.

Table 1. Experimental design for simulated waste drum VOC transport experiments.

\begin{tabular}{|c|c|c|c|c|}
\hline Test period & Drum number & Sludge mixture ${ }^{a}$ & Small bag & Liner \\
\hline \multirow[t]{4}{*}{1} & 1 & $\mathbf{A}$ & absent & open \\
\hline & 2 & A & absent & open \\
\hline & 3 & A & absent & open \\
\hline & 4 & A & absent & open \\
\hline \multirow[t]{4}{*}{2} & 1 & B & present $^{b}$ & open \\
\hline & 2 & $\mathbf{B}$ & present $^{b}$ & open \\
\hline & 3 & B & present $^{b}$ & sealed $^{c}$ \\
\hline & 4 & B & present $^{b}$ & sealed ${ }^{c}$ \\
\hline
\end{tabular}

a. Sludge mixture $\underline{\mathrm{A}}(\sim 100 \mathrm{~g}$ each drum) contains approximately a $34 \%$ Regal Texaco oil, $4 \%$ methylene chloride, $25.5 \%$ carbon tetrachloride, $13 \%$ TCA, 5\% TCE, 5\% Freon-113, and 14\% calcium silicate. Sludge mixture B ( $-200 \mathrm{~g}$ each drum) contains approximately a $34 \%$ Regal Texaco oil, $10 \%$ methanoll, $10 \%$ cyclohexane, $10 \%$ TCA, $10 \%$ toluene, $10 \%$ p-xylene, and $15 \%$ calcium silicate.

b. Two small bags were present in each drum.

c. Sealed for the first 31 days of test period. 


\subsection{Automated Experimental Configuration}

The same experimental configuration used for the automated sampling and analysis of VOC concentrations in unsteady-state VOC transport experiments ${ }^{2}$ was used for these experiments and is shown in Figure 2. Each of the four lab-scale waste drums in the configuration was a scaled-down version of a DOT $17 \mathrm{C} 55$-gal drum. Each waste drum contained a 90-mil high-density rigid polymer drum liner. The drum liner was a scaled-down Type III liner with a removable lid that was bolted on with a metal closure ring. A 0.375 -in. hole was drilled in the drum lid so that a NFT-020 (Nuclear Filter Technology Corp.) carbon-composite filter could be screwed into the lid. In Trial 1, the filter vent was located $4.3 \mathrm{in} .(10.8 \mathrm{~cm})$ from the outside edge of the drum lid. In Trial 2, the filter vent was located 2 in. $(5.1 \mathrm{~cm})$ from the center of the drum. In both cases, a hole was drilled in the liner lid directly below the filter vent. Inside the drum liner was a large polyethylene bag supported by a wire cage that either contained simulated waste sludge or smaller polyethylene bags that contained the simulated waste sludge.

Headspace samples were collected by evacuating the manifold system to a vacuum and then back-filling the gas sampling loops. The gas sample flowed into the selected sampling loop until the pressure equilibrated to ambient pressure. Between samples, the automated gas sampling system evacuated the sampling manifold and gas sampling loops. Samples were transferred from the gas sampling loop to the gas chromatograph injector and analyzed by a flame ionization detector.

\subsection{Experimental Procedures}

A batch of simulated waste sludge with the composition listed in Table 2 was prepared for use in Trial 1 experiments. Calcium silicate was added to the solution until the solvents were

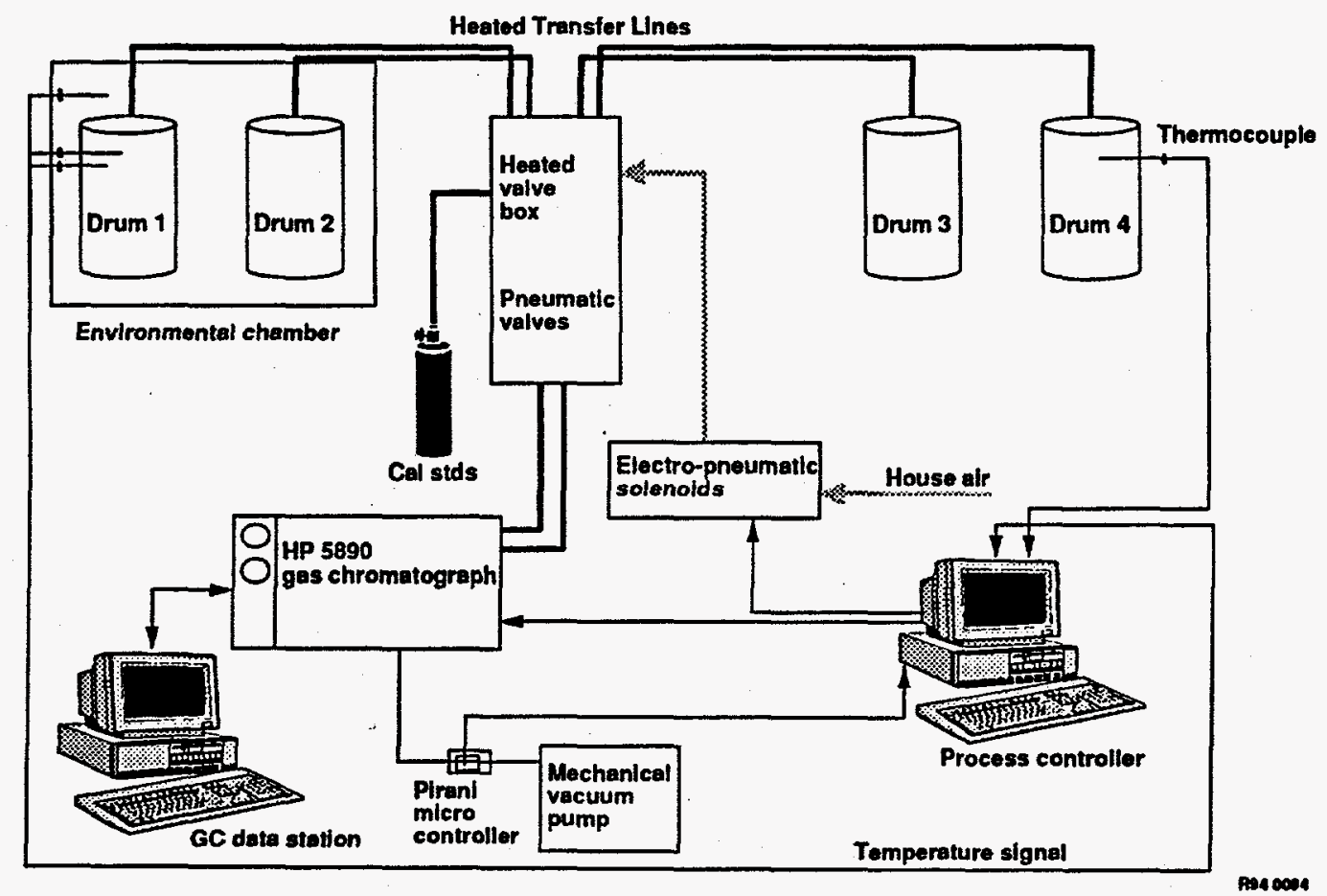

Figure 2. Automated VOC transport experimental configuration. 
Table 2. Trial 1 sludge mixture.

\begin{tabular}{lcc}
\multicolumn{1}{c}{ Component } & Weight $(\mathrm{g})$ & Weight (\%) \\
\hline Regal Texaco oil & 150.5 & 33.7 \\
Methylene chloride & 18.2 & 4.1 \\
Carbon tetrachloride & 113.9 & 25.5 \\
1,1,1-trichloroethane & 58.7 & 13.1 \\
Trichloroethane & 21.4 & 4.8 \\
Freon 113 & 22.6 & 5.1 \\
Calcium silicate & 61.8 & 13.8 \\
\hline
\end{tabular}

absorbed and the sludge formed a thick paste. The sludge was separated into four $500-\mathrm{ml}$ glass jars that were capped with teflon-lined lids. Each jar contained approximately $100 \mathrm{~g}$ of sludge. One jar was opened and placed inside the large bag of each waste drum just before the bag was closed with a taped horsetail tie. A horsetail tie is formed by twisting together the open end of the bag and wrapping with tape. The same method was used for preparing horsetail ties in earlier VOC transport experiments. ${ }^{2}$

A batch of simulated waste sludge with the composition listed in the Table 3 was prepared for use in Trial 2 experiments. Calcium silicate was added to the solution until the solvents were completely absorbed and the sludge formed a thick paste. The sludge was separated into eight 500 -ml glass jars and sealed with teflon lids. Each jar contained approximately $100 \mathrm{~g}$ of sludge. One jar was opened and placed in each small bag just before it was heat sealed and placed in a waste drum. Each bag was then filled with 3.5 liters of hydrocarbon-free air to prevent the bag

Table 3. Trial 2 sludge mixture.

\begin{tabular}{lll}
\hline \multicolumn{1}{c}{ Component } & Weight (g) & Weight (\%) \\
\hline Regal Texaco oil & 360.4 & 33.9 \\
Methanol & 107.5 & 10.1 \\
Cyclohexane & 106.3 & 10.0 \\
1,1,1-trichloroethane & 108.1 & 10.2 \\
Toluene & 109.8 & 10.3 \\
p-xylene & 107.9 & 10.2 \\
Calcium silicate & 163.3 & 15.4 \\
\hline
\end{tabular}


from collapsing upon itself. At the beginning of the test period, two drums had a filter vent in the drum lid and an opening in the drum liner lid, while the other two drums had a long metal plug wrapped with teflon tape placed in the opening of the drum lid and drum liner. In this way, a sealed drum could be vented quickly by simply removing the plug. Gas samples from the headspace of each bag and from underneath the drum lid were generally collected from each drum twice a week. The total trial period lasted approximately 90 days.

\subsection{Quality Control}

\subsubsection{Quality Control Samples}

Initial calibration curves, continuing calibration standards, system blanks, and sample duplicates were part of the quality control procedures used to ensure the quality of the experimental data. An initial calibration curve plots the concentrations of the known analyte standard against the instrument response (area counts) to the analyte. A three-point fivereplicate external calibration curve was prepared for each target compound before the start of each sampling day. The liquid standards were run randomly on the autosampler, and data were fitted to a curve by linear regression. At different times throughout the test period, the calibration range was modified accordingly so that all sample area counts were within the calibration curve. Sample duplicates were collected for each waste drum from one of the headspaces on each sampling day. The percent recovery for each sample duplicate was calculated to evaluate the precision of the automated sampling and analytical system. The percent recovery is defined as the ratio of the duplicate concentration to sample concentration multiplied by 100 .

\subsubsection{Additional Quality Checks}

The following baseline checks were made to ensure that the system performed as designed:

1. The process controller block configuration controlling the pneumatic solenoids was confirmed to verify that a specified valve opened and closed when actuated.

2. Sequential timing was verified to ensure quantitative sample transfer before any sample analysis.

3. The maximum attainable vacuum pressures for an open and closed manifold system were determined. Pressure set points were based on these measurements and were modified slightly as needed to ensure correct sequencing.

4. Temperature thermocouples were standardized using a calibrated thermocouple and thermometer. At the beginning of each test period and randomly throughout the experiments, the temperatures of the heated transfer lines and manifold valve box were checked.

5. During the preparation of the polyethylene bags, the bulkhead feedthroughs were attached to the bag and leak tested before the bag was placed in the waste drum. 


\section{EXPERIMENTAL AND MODEL RESULTS}

\subsection{VOC Transport Experiments}

The TCA concentrations measured in the drum and large bag headspaces for each drum in Trial 1 are shown in Figure 3. The TCA concentrations measured in the drum and small bag headspaces for each drum in Trial 2 are shown in Figure 4. The rate of change in the VOC concentration during Trial 2 was less than in Trial 1 because of the larger quantity of simulated sludge placed in the drums. These trends were observed for other VOCs. The other measured VOC concentrations from Trials 1 and 2 are listed in Appendix A.

In Trial 1, the gas sampling lines in Drum 1 pulled out of the drum and large bag bulkhead feedthroughs. Correction of the problem required opening all layers of confinement; therefore, data collection from the drum was discontinued. At the completion of each trial, all drums were disassembled to determine if any of the layers of confinement had been damaged or compromised. The drum lid seals, drum feedthrough septa, large bag feedthrough septa, large bags, and small bags remained intact throughout both trials. During both trials, small amounts of the simulated waste sludge spilled from the jars and came in contact with the surrounding polyethylene bag. During Trial 2, the horsetail ties on the large bags in Drums 3 and 4 became loose. The piece of tape folded over the end of the horsetail had come undone, and part of the horsetail had unwound. The tape at the base of the horsetail was still intact.

During Trial 1, the relative standard deviation for the initial calibration standards was less than $15 \%$ with only a few exceptions. During Trial 2 , the relative standard deviation never exceeded $15 \%$. The coefficient of determination, $\mathrm{r}^{2}$, is a measure of linearity. An absolute value of unity is indicative of perfect linearity. During Trial 1 , the values of $r^{2}$ for the initial calibration curves exceeded 0.99 in most cases. During Trial 2, the values of $r^{2}$ exceeded 0.98 in most cases. On two occasions, initial calibration curves for cyclohexane had an $r^{2}$ less than 0.96. Precision was assessed through the analysis of sample duplicates and expressed as the percent recovery. Percent recoveries were generally between $95 \%$ and $105 \%$ during Trial 1 and were generally between $90 \%$ and $110 \%$ during Trial 2 . The percent recovery for p-xylene during Trial 2 ranged between $80 \%$ and $120 \%$.

\subsection{Model Calculations}

The VOC concentrations throughout a waste drum were estimated using the model equations presented in Section 2. Model parameters were measured or estimated from available process knowledge.

\subsubsection{Surface Areas}

The large bag dimensions were 33 in. $(83.8 \mathrm{~cm})$ wide and $36 \mathrm{in} .(91.4 \mathrm{~cm})$ long. Allowing for approximately 6 in. $(15.2 \mathrm{~cm})$ of material to form the horsetail, the resulting maximum surface area was estimated to be $1,980 \mathrm{in}^{2}\left(12,800 \mathrm{~cm}^{2}\right)$. The dimensions of the heat-sealed small bags were 12 in. $(30.5 \mathrm{~cm})$ by 18 in. $(45.7 \mathrm{~cm})$. The maximum surface area of each small bag was 


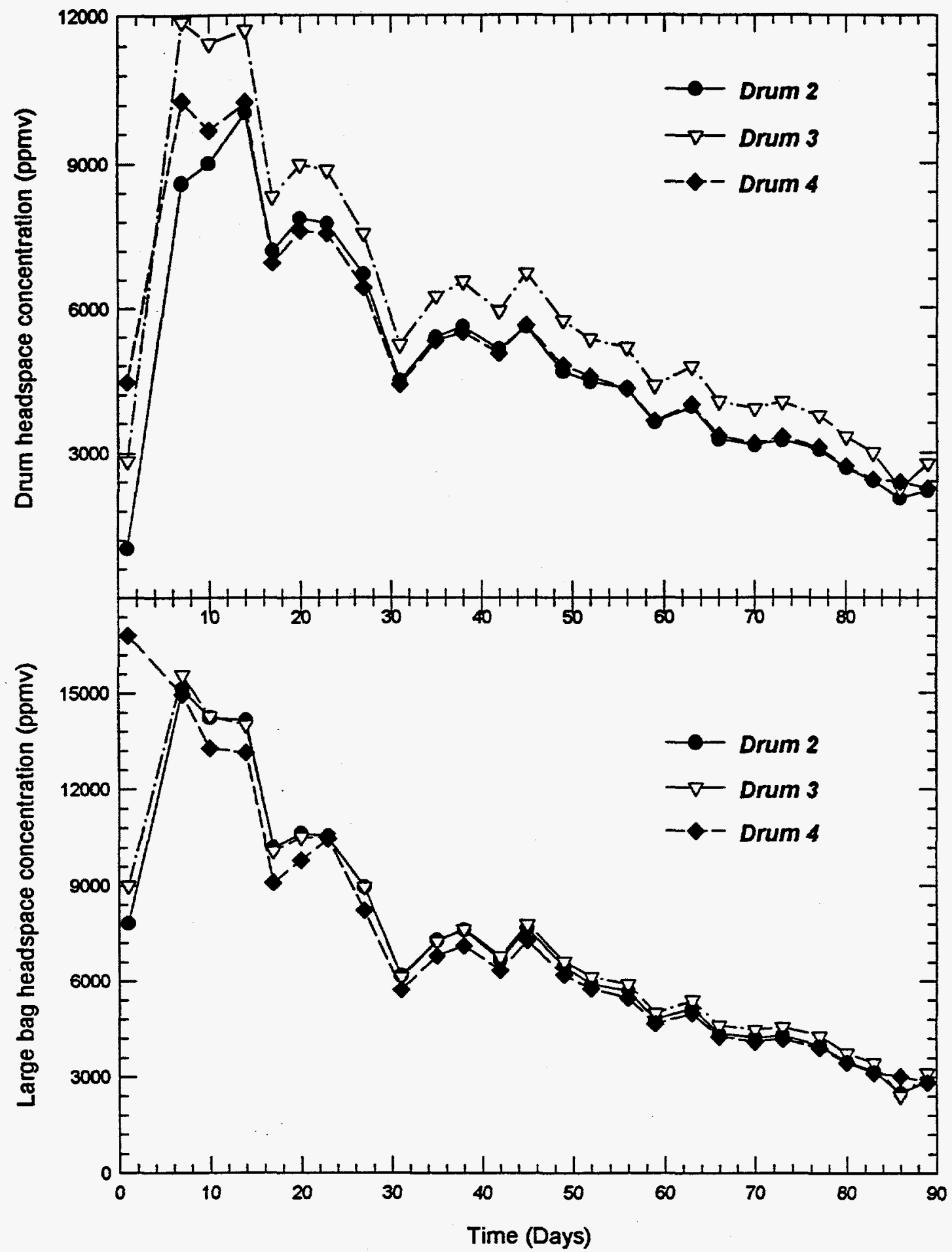

Figure 3. The measured TCA concentration within drum headspace and large bag headspace of lab-scale waste drums during Trial 1. 


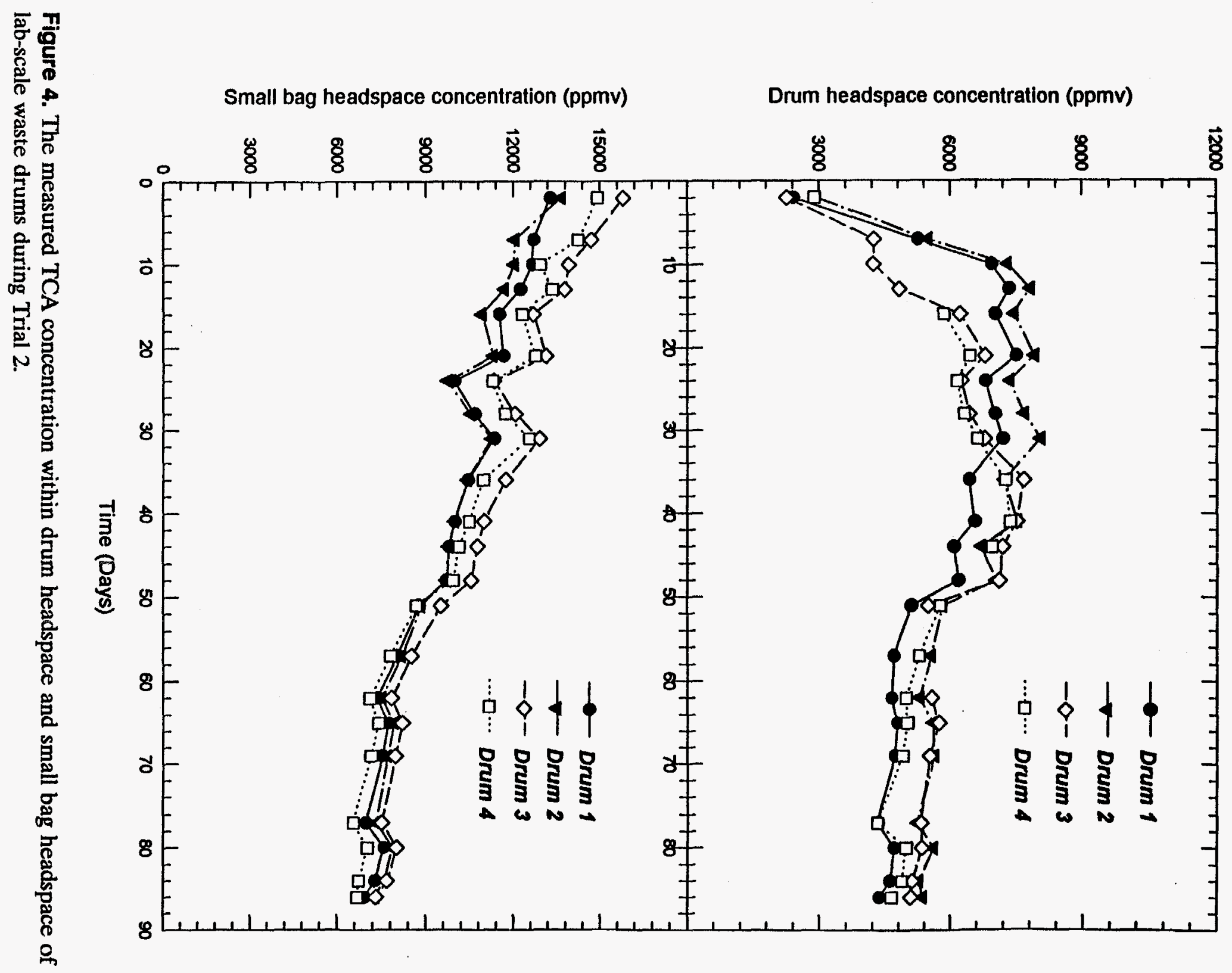


432 in. $^{2}\left(2,790 \mathrm{~cm}^{2}\right)$. The cross-sectional area of the opening in the drum liner lid was calculated to be 0.11 in. $^{2}\left(0.71 \mathrm{~cm}^{2}\right)$ in Trial 1 and 0.09 in. $^{2}\left(0.60 \mathrm{~cm}^{2}\right)$ in Trial 2.

\subsubsection{Transport Lengths}

All polyethylene bags were $0.004 \mathrm{in} .(0.01 \mathrm{~cm})$ thick. The average thickness of the liner lid where the opening was located was $0.19 \mathrm{in} .(0.47 \mathrm{~cm})$. The diffusional length across the drum liner lid was assumed equal to the sum of the opening diameter and lid thickness.

\subsubsection{VOC Transport Properties}

The VOC permeability coefficients were measured using a mixed-component chromatographic detection method ${ }^{2}$ and are listed in Table 4. The diffusivities of most VOCs in air at a given temperature and pressure were identified in the literature. ${ }^{3}$ In the case where diffusivity data could not be identified, the VOC diffusivity in air was estimated using the Slattery equation ${ }^{4}$

$$
D_{A B}=2.745 \times 10^{-8} \frac{T^{1.823}}{\text { II }}\left[p_{c A} p_{c B}\right]^{1 / 3}\left[T_{c A} T_{c B}\right]^{-0.495}\left[\frac{1}{M_{A}}+\frac{1}{M_{B}}\right]^{1 / 2}
$$

where

$$
\begin{aligned}
& \mathrm{D}_{\mathrm{AB}}=\text { mass diffusivity for } \operatorname{VOC}(\mathrm{A}) \text {-air }(B) \text { system, } \mathrm{m}^{2} \mathrm{~s}^{-1} \\
& \text { II }=\text { pressure, atm } \\
& \mathrm{p}_{\mathrm{ci}}=\text { critical pressure of species } \mathrm{i} \text {, atm } \\
& \mathrm{T}_{\mathrm{ci}}=\text { critical temperature of species } \mathrm{i}, \mathrm{K} \\
& \mathrm{M}_{\mathrm{i}}=\text { molecular weight of species } \mathrm{i} .
\end{aligned}
$$

The same equation was used to correct for any difference in temperature and pressure observed in the experiments. The VOC diffusion characteristic across a NFT-020 filter vent has been determined for all VOCs used in the two trials. ${ }^{5}$ An empirical correlation was developed based on these results that estimated the VOC diffusion characteristic from the estimated ratio of hydrogen-to-VOC diffusivity at given conditions and the hydrogen diffusion characteristic across a NFT-020 filter vent

$$
D_{v a c}^{*}=\gamma D_{H_{2}}^{*}\left(\frac{V_{c, H_{2}}}{V_{c, v o c}}\right)^{0.333}\left[\frac{D_{v o c-a i r}}{D_{H_{2} \text {-air }}}\right]
$$


Table 4. Vapor permeability coefficient across a polyethylene bag at $25^{\circ} \mathrm{C}$ at a specific VOC concentration in air.

Permeability

Concentration

Compound

(ppmv)

$\mathrm{Ba}^{\mathrm{a}}$

$\left[\mathrm{m}^{3}(\mathrm{STP}) \mathrm{m} /(\mathrm{N} \mathrm{s})\right]$

$\left(\mathrm{x} 10^{15}\right)$

Methylene chloride

1006

Carbon tetrachloride

295

1,1,1-trichloroethane

994

Trichloroethylene

300

Freon-113

1010

Methanol

100

Cyclohexane

745

Toluene

501

p-xylene

501

$232 \pm 15^{b}$

$181 \pm 39$

$83.1 \pm 3.4$

$660 \pm 15$

$34.3 \pm 1.3$

$135 \pm 35$

$12.4 \pm 1.7$

$668 \pm 121$

$811 \pm 48$
$1.74 \pm 0.11$

$1.36 \pm 0.29$

$0.62 \pm 0.03$

$4.95 \pm 0.11$

$0.26 \pm 0.01$

$1.01 \pm 0.26$

$0.093 \pm 0.013$

$5.01 \pm 0.91$

$6.08 \pm 0.36$

a. $\mathrm{Ba}=10^{-10} \mathrm{~cm}^{3}(\mathrm{STP}) \mathrm{cm}^{-1} \mathrm{~s}^{-1}\left(\mathrm{~cm} \mathrm{Hg}^{-1}\right.$.

b. Standard deviation.

where

$$
\begin{array}{ll}
\mathrm{D}_{\mathrm{i}}^{*} & =\text { diffusion characteristic for species } \mathrm{i} \text { across filter vent, } \mathrm{mol} \mathrm{s} \mathrm{s}^{-1} \\
\gamma & =\text { empirical parameter }=1.2 \\
\mathrm{~V}_{\mathrm{c}, \mathrm{i}} & =\text { critical volume of species } \mathrm{i}, \mathrm{m}^{3} \mathrm{~mol}^{-1} \\
\mathrm{D}_{\mathrm{i}-\mathrm{a} i \mathrm{i}} & =\text { diffusivity of species } \mathrm{i} \text { in air, } \mathrm{m}^{2} \mathrm{~s}^{-1} .
\end{array}
$$

\subsubsection{Temperature and Pressure}

The waste drums were maintained at ambient room temperature and pressure. A constant temperature of $76.5^{\circ} \mathrm{F}\left(24.7^{\circ} \mathrm{C}\right)$ and a constant pressure of 644.8 torr were used in all model calculations. 


\subsection{Model Results}

Model calculations were performed using the computer program listed in Appendix B. The program was run on an IBM PS/2 Model 70 using a Lahey FORTRAN compiler. In Figures 5 and 6, the daily average concentration ratios from vented drums are compared with model estimates of the concentration ratio during Trials 1 and 2, respectively. The absolute value of the error bar assigned above and below the daily concentration ratio is equal to twice the pooled estimate of the standard error of the mean. There is approximately a $95 \%$ certainty that the actual VOC concentration ratio lies within the region covered by the error bars. Assuming that the daily variance between the experimental concentration ratios in all the lab-scale waste drums is approximately the same for each day, the pooled estimate of the standard error of the mean, $S_{x}$, was defined as

$$
S_{x}=\sqrt{\frac{\sum_{i=1}^{N} s_{i}^{2} / N}{n}}
$$

where

$$
\begin{aligned}
& \mathbf{s}_{\mathrm{i}}^{2}=\text { sample variance for } \mathrm{i}^{\text {th }} \text { test day } \\
& \mathrm{N}=\text { total number of test days } \\
& \mathbf{n}=\text { total number of drums. }
\end{aligned}
$$

In Trial 1 , three drums were used to calculate the daily sample variance. During Trial 2 , two pooled estimates were calculated. The two drums vented at the beginning of the test period were used to calculate the sample mean and variance over the first 31 days. After 31 days, the other waste drums were vented. All four drums were used to calculate the pooled estimate of the standard error of the mean for the time period beginning after day 31 . The concentration ratio in the unvented drums quickly approached the values in the vented drums upon removal of the plug.

Model predictions of the concentration ratios were calculated using experimental and estimated values for the VOC diffusion characteristic across the NFT-020 filter vent. A comparison of the two model results shows that the higher estimated concentration ratio is associated with a lower VOC diffusion characteristic. The difference between model results was less than one standard deviation associated with the experimental average concentration ratio. The ratio of the drum headspace concentration to the innermost layer of confinement concentration was calculated to minimize daily fluctuations that affected all measurements on a given day, as well as demonstrate when the transport rates were nearly equivalent. Most concentration ratios approached a constant value indicative of nearly equal transport rates from the innermost layer of confinement and the drum headspace. During Trial 1 , the time required for the concentration ratio to reach a constant value varied between 10 and 50 days, depending on the VOC. During Trial 2, it took much longer for the concentration ratio for toluene and p-xylene to reach a constant value. Given sufficient time, a maximum and near-constant concentration ratio should be achieved for all VOCs. The time it took to reach a near-constant 


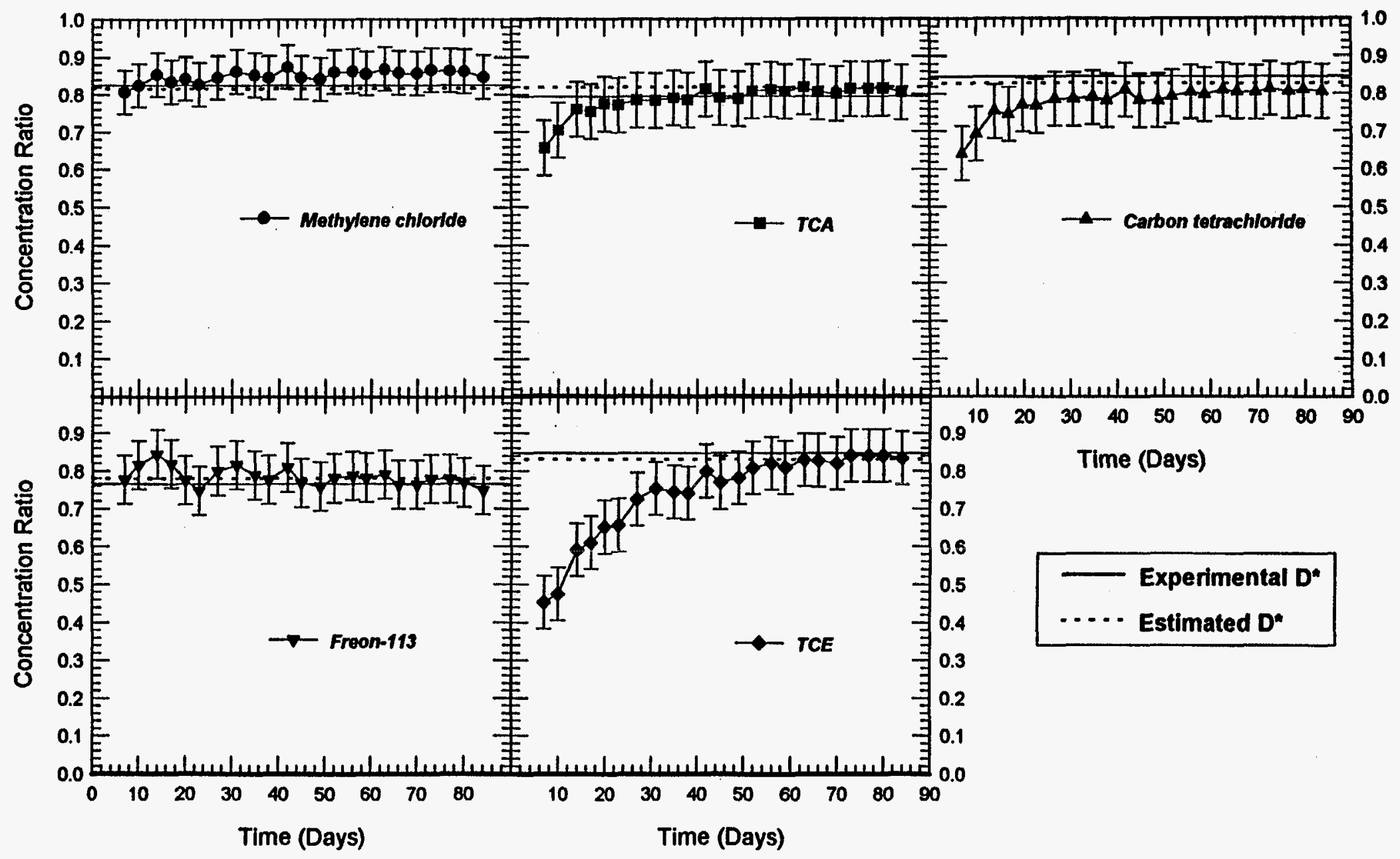

Figure 5. Daily average drum headspace-to-large bag headspace VOC concentration ratio and model predictions during Trial 1. 


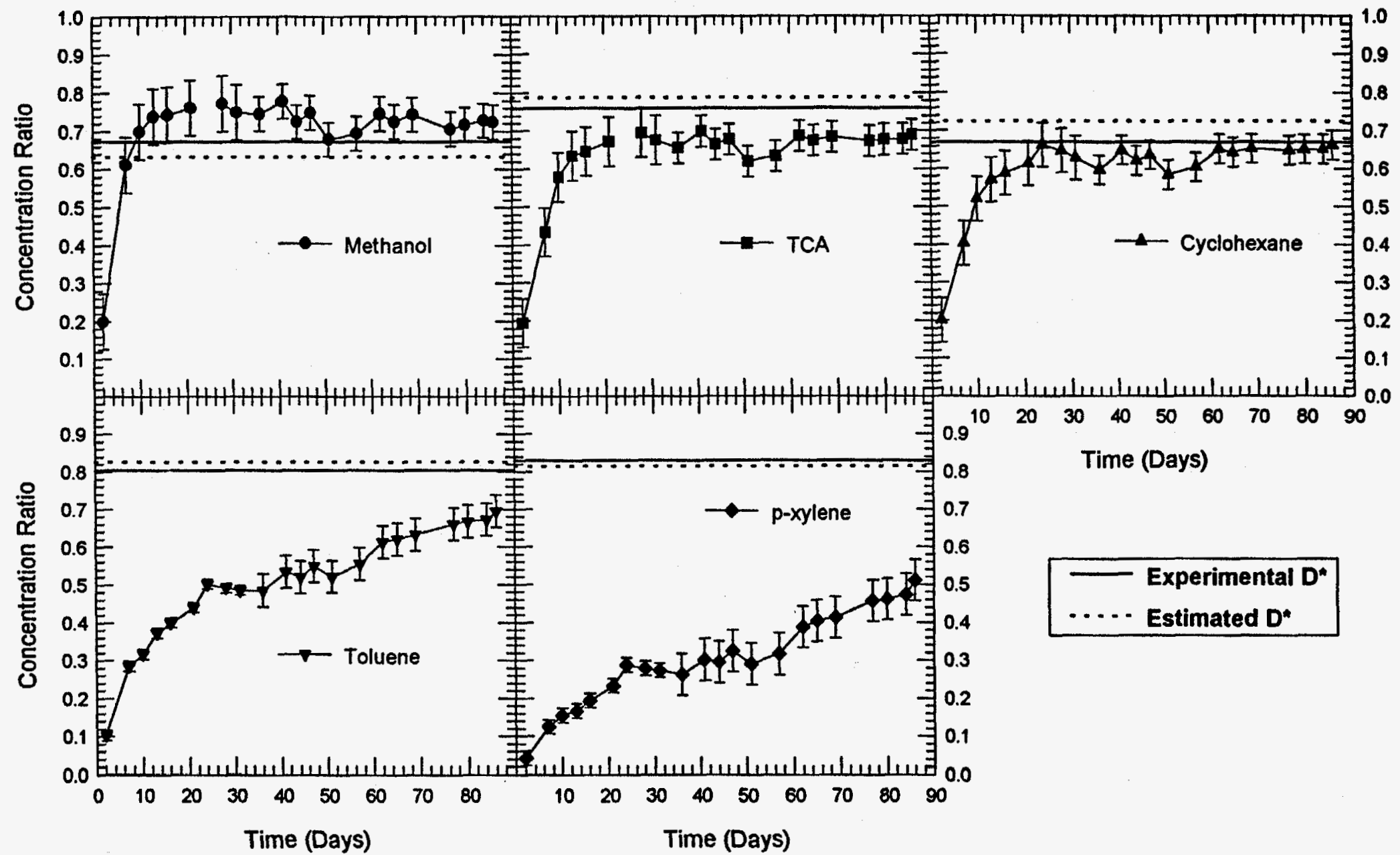

Figure 6. Daily average drum headspace-to-small bag headspace VOC concentration ratio and model predictions during Trial 2. 
value was a function of the waste drum configuration and the VOC source. Tables 5 and 6 show that the time decreased with increasing VOC vapor pressure. The VOC vapor pressure was estimated using the Antoine equation. 6,7

The drum headspace-to-small bag concentration ratio curves in Figure 6 indicate that VOCs entered the drum headspace of Drums 3 and 4 even when the drum liner were not vented. It is possible that the taped pin used to seal the drum and drum liner lids did not achieve a perfect seal. It is more probable that the VOCs diffused through the butadiene-styrene gasket on the drum liner lid. In addition, while the concentration ratio in the unvented drums was less than in the vented drums, the ratios in the unvented quickly approached the values in the other drums after the pin was removed. This fact suggests if an opening in the liner lid and a filter vent can be installed without removing the drum lid, then the drum could be sampled shortly after vent installation. However, a drum that requires the lid to be removed to insert an opening in the liner lid should be treated as a newly packaged drum. In this case, a minimum waiting period must pass before gas samples taken from the vented drums can be considered representative of the gas concentration throughout the void volume of the drum. The minimum waiting time

Table 5. Comparison of VOC vapor pressure and approximate average time when near-constant drum-headspace-to-large-bag VOC concentration ratio was reached during Trial 1.

\begin{tabular}{lcc} 
Compound & $\begin{array}{c}\text { Vapor pressure } \\
\text { (mm Hg) }\end{array}$ & $\begin{array}{c}\text { Time } \\
\text { (days) }\end{array}$ \\
\hline Methylene chloride & 430.5 & 14 \\
Freon-113 & 334.4 & 18 \\
$1,1,1-T C A$ & 133.5 & 52 \\
Carbon tetrachloride & 115.2 & 55 \\
TCE & 69.1 & 62
\end{tabular}

Table 6. Comparison of VOC vapor pressure and approximate average time when near-constant drum-headspace-to-small-bag VOC concentration ratio was reached during Trial 2.

\begin{tabular}{lcc} 
Compound & $\begin{array}{c}\text { Vapor pressure } \\
(\mathrm{mm} \mathrm{Hg})\end{array}$ & $\begin{array}{c}\text { Time } \\
\text { (days) }\end{array}$ \\
\hline 1,1,1-TCA & 133.5 & 14 \\
Methanol & 126.4 & 14 \\
Cyclohexane & 97.6 & 24 \\
Toluene & 28.4 & $>86$ \\
p-xylene & 8.8 & $>86$
\end{tabular}


before sampling can take place is a function of the VOCs in the waste, the amount of VOCs in the waste matrix, and the waste drum configuration.

\subsection{Effect of Parameter Values on Model Results}

\subsubsection{VOC Diffusion}

By combining Equations (3) and (4) and recalling the assumption of no VOCs outside the drum, the relative concentration difference between the drum headspace and the drum liner headspace as compared with the drum headspace concentration is defined as

$$
\frac{\Delta C_{n-1}}{c_{n}}=\frac{D^{*}}{D} \frac{\Delta x_{d} R T}{A_{d} P}
$$

The concentration difference will decrease as the VOC diffusion characteristic across the filter vent decreases. The latter can be accomplished by changing the filter vent design. The assumed diffusion length across the liner lid increases linearly as the opening diameter increases. However, because the cross-sectional area is a linear function of the square of the opening diameter, the concentration difference will decrease as the opening diameter increases.

Comparison of model calculations using actual and estimated values for the VOC diffusion characteristic indicate some difference in the predicted concentration ratio. The smaller value resulted in a higher estimate of the VOC concentration ratio. The measured VOC diffusion characteristic was an average value determined for six filter vents of similar design. ${ }^{5}$ Variance about the average value resulted from the design of the filter vent and filter medium. Model estimates for both trials were calculated using the mean VOC diffusion characteristic as well as values that were two standard deviations above and below the mean and are shown in Figures 7 and 8. The effect on the estimated VOC concentration ratio is dependent upon the relative size of the standard deviation. When the diffusion characteristic standard deviation was greater than $15 \%$ of the mean, the difference between model results using the mean and the bounding value for the diffusion characteristic was generally greater than twice the pooled estimate of the standard error. The VOCs that fall in this category are methanol, cyclohexane, and p-xylene. In the future, smaller variances in the measured VOC diffusion characteristic may result by simply sampling a larger population of filter vents.

\subsubsection{VOC Permeation}

The relative difference between the concentration in the inner bag headspace and the drum headspace is defined by combining Equations (1) and (4)

$$
\frac{\Delta c_{1}}{c_{n}}=\frac{D^{*} R T / P}{P A_{p} P / \Delta x_{p}}=\left(\frac{D^{*}}{\rho}\right)\left(\frac{\Delta x_{p} R T}{A_{p} P^{2}}\right) \text {. }
$$

The concentration difference across the inner bag will decrease with increasing permeable surface area or decreasing bag thickness. These variables are a function of the waste packaging 


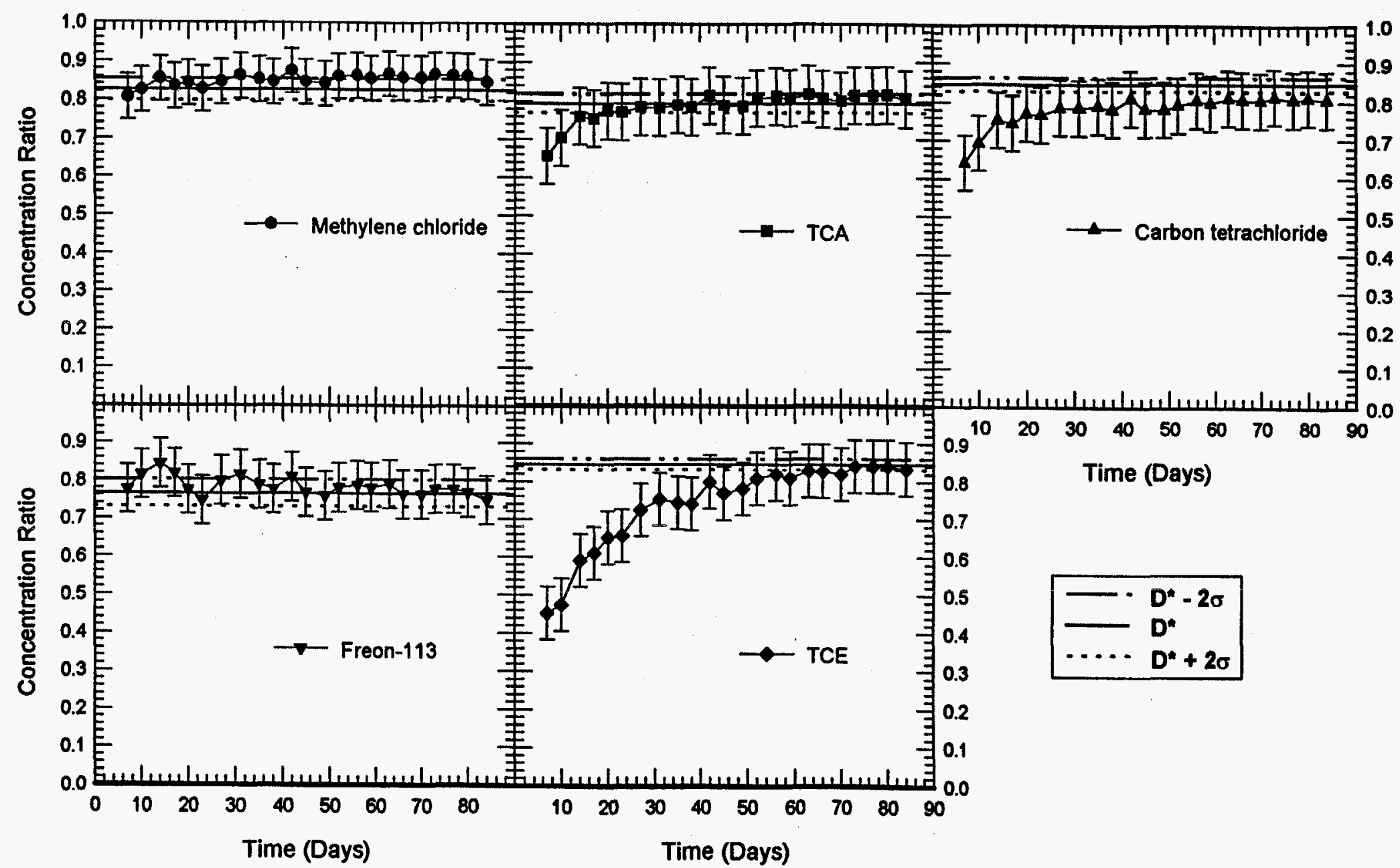

Figure 7. Predicted VOC concentration ratios in Trial 1 using a VOC diffusion characteristic defined by the mean value, $\mathrm{D}^{*}$, and the standard deviation about the mean, $\sigma$. 


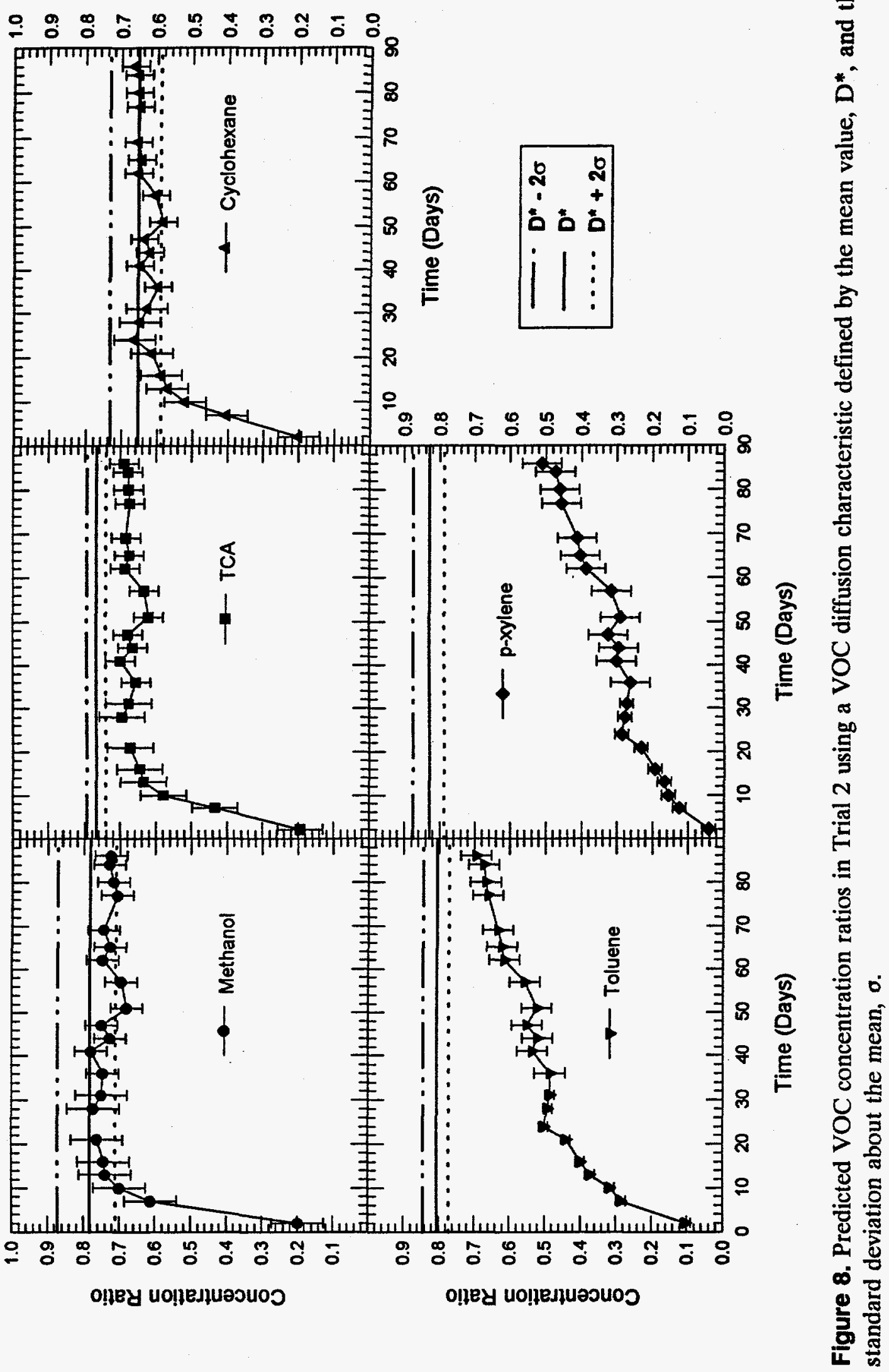


configuration and will vary from drum to drum. In addition, a decreasing VOC diffusion characteristic across the filter vent or increasing VOC permeability across the polymer bag will lead to a decrease in the concentration difference. For a given filter vent design, these two parameters are a function of the VOC in the waste drum. Because the range of VOC diffusion characteristics across a filter vent is relatively narrow, one can estimate the permeability value where the concentration difference becomes insignificant. Temperature and pressure affect the concentration difference, but there is little control over these parameters.

Vapor permeability coefficients generally increase with increasing vapor concentration. All VOC permeabilities listed in Table 4 and used in model calculations were measured at vapor concentrations less than those measured during the lab-scale waste drum experiments. Thus, the predicted concentration difference across a polymer bag was assumed to be equal to or greater than the actual. Equation (14) can be used to estimate the change in the concentration difference with increasing VOC permeability. In the case where the estimated concentration difference is small, an increase in the permeability value will decrease an already small value. For low-permeability VOCs, the permeability may be two or three times larger at higher vapor concentrations. Depending on the waste drum configuration, the use of a larger permeability value could significantly reduce the estimated concentration difference. The use of a VOC permeability measured across an identical or similar polymer bag at VOC vapor concentrations less than those that exist under actual conditions will result in a conservative estimate of the actual concentration difference across the bag.

Equation (14) can demonstrate the impact of assumed permeable surface area. In the experiments, the maximum surface area of the small and large bags are known by direct measurement. In actual waste drums, the surface area will be estimated from process knowledge or indirectly observed by real-time radiography. Because the estimated concentration difference is inversely proportional to the available surface area, a conservative approach would assume the smallest likely value.

\subsection{Experimental and Model Refinements}

The presence of multiple layers of small or large polymer bags is probable. For model calculations, the multiple layers will be assumed to be equivalent to a single layer with a thickness equal to the sum of all the individual layers. This assumption will be investigated during the gas sampling and waste characterization of actual vented waste drums.

A conservative application of the transport model to actual waste drums would be to give less than full credit for the total permeable surface area of the bags. 


\section{CONCLUSIONS}

A VOC transport model accurately estimated the VOC concentration in the headspace of the innermost layer of confinement of a lab-scale vented waste drum containing simulated waste sludge. The model estimates the VOC concentration in the drum based on the measured VOC concentration beneath the drum lid and other model parameters that are determined or estimated from process knowledge of the drum contents and the waste drum configuration. These model parameters include the VOC diffusion characteristic across the filter vent, VOC diffusivity in air, size of opening in the drum liner lid, the type and number of layers of polymer bags surrounding the waste, VOC permeability across the polymer, and the permeable surface area of the polymer bags. Model equations indicate that knowledge of some parameters is not important in cases where the estimated concentration difference between layers is expected to be small. 


\section{REFERENCES}

1. U. S. Department of Energy, Quality Assurance Program Plan for the Waste Isolation Pilot Plant Experimental-Waste Characterization Program, DOE/EM/48063-1, Rev. 1, July 1991.

2. K. J. Liekhus, G. L. Gresham, E. S. Peterson, C. Rae, N. J. Hotz, and M. J. Connolly, Modeling Unsteady-State VOC Transport in Simulated Waste Drum, EGG-WM-10823 Rev. 1, EG\&G Idaho, January 1994.

3. G. A. Lugg, "Diffusion Coefficients of Some Organic and Other Vapors in Air," Analytical Chemistry, 40, 1073 (1968).

4. R. B. Bird, W. E. Stewart, and E. N. Lightfoot, Transport Phenomena, John Wiley, New York, 1960.

5. K. J. Liekhus and D. A. Johnson, New Method to Estimate VOC Diffusion Characteristic across NFT-020 Carbon Composite Filter, EDF RWMC-643, Rev. 1, EG\&G Idaho, December 1993.

6. R. M. Felder and R. W. Rousseau, Elementary Principles of Chemical Processes, Second edition, John Wiley, New York, 1986.

7. J. A. Dean (ed.), Lange's Handbook of Chemistry, 13th edition, McGraw-Hill, New York, 1985. 


\section{Appendix A}

Measured VOC Concentrations in Lab-scale Waste Drums

A-1 
A-2 
Table A-1. Measured VOC concentration (ppmv) in Drum 2 headspaces during Trial 1.

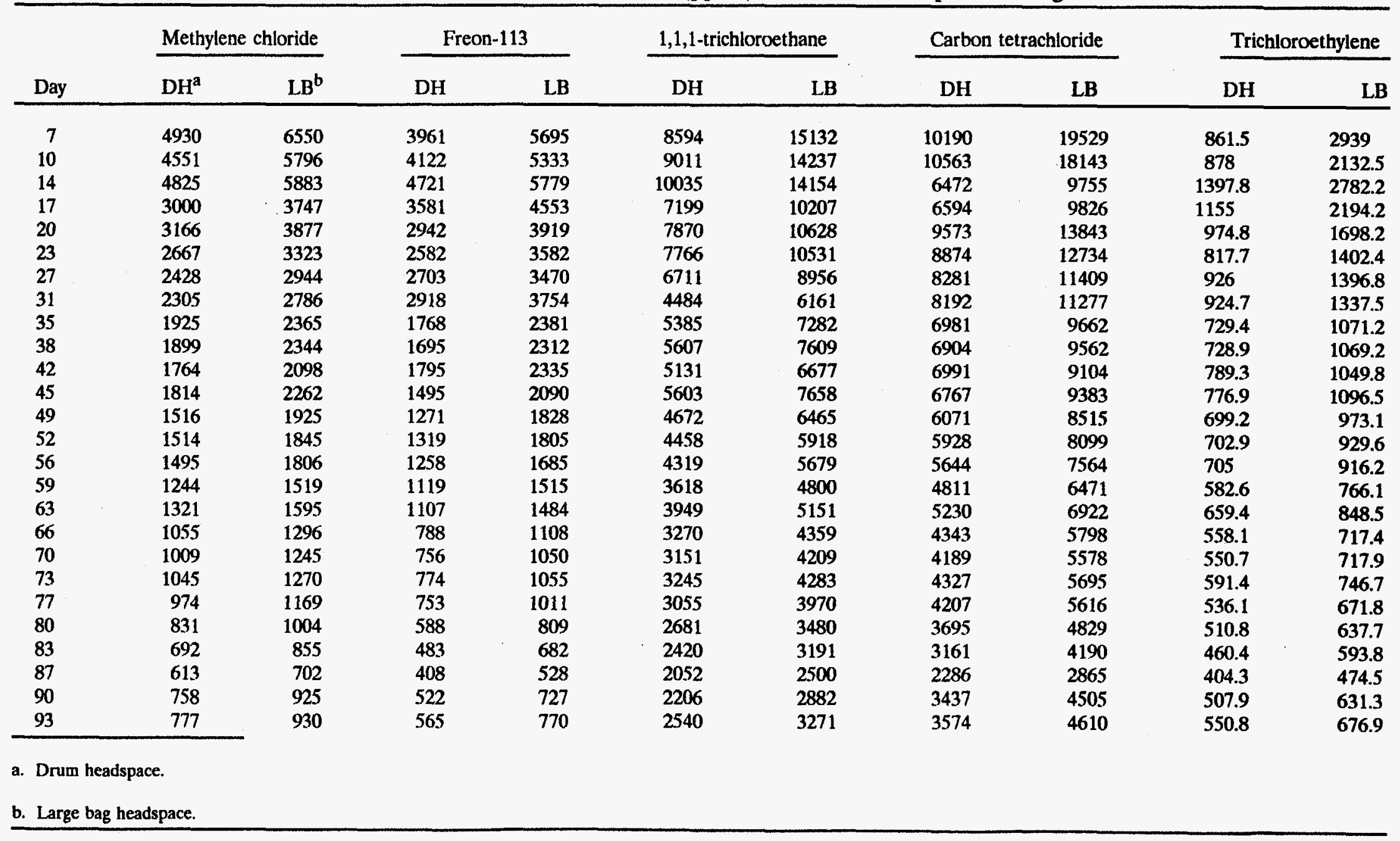


Table A-2. Measured VOC concentration (ppmv) in Drum 3 headspaces during Trial 1.

\begin{tabular}{|c|c|c|c|c|c|c|c|c|c|c|}
\hline \multirow[b]{2}{*}{ Day } & \multicolumn{2}{|c|}{ Methylene chloride } & \multicolumn{2}{|c|}{ Freon-113 } & \multicolumn{2}{|c|}{ 1,1,1-trichloroethane } & \multicolumn{2}{|c|}{ Carbon tetrachloride } & \multicolumn{2}{|c|}{ Trichloroethylene } \\
\hline & $\mathbf{D H}^{\mathbf{a}}$ & $\mathrm{LB}^{\mathbf{b}}$ & DH & LB & DH & LB & DH & LB & DH & LB \\
\hline 7 & 5418 & 6081 & 4577 & 5307 & 11875 & 15575 & 14740 & 20538 & 1435.3 & 2611.5 \\
\hline 10 & 4852 & 5459 & 4388 & 6033 & 11437 & 14287 & 14141 & 18572 & 1368.4 & 2263.5 \\
\hline 14 & 5022 & 5592 & 4798 & 5479 & 11708 & 14004 & 7891 & 9771 & 1945 & 2822.6 \\
\hline 17 & 3131 & 3561 & 3658 & 4304 & 8326 & 10092 & 7896 & 9832 & 1565.2 & 2199.8 \\
\hline 20 & 3317 & 3703 & 3034 & 3662 & 8987 & 10516 & 11383 & 13710 & 1274.9 & 1691.6 \\
\hline 23 & 2807 & 3188 & 2676 & 3346 & 8874 & 10493 & 10531 & 12761 & 1069.9 & 1408.4 \\
\hline 27 & 2507 & 2834 & 2730 & 3272 & 7563 & 8959 & 9652 & 11528 & 1134.1 & 1402.8 \\
\hline 31 & 2455 & 2685 & 3077 & 3562 & 5226 & 6125 & 9666 & 11339 & 1127.7 & 1340.7 \\
\hline 35 & 2066 & 2279 & 1901 & 2240 & 6252 & 7246 & 8285 & 9683 & 896.6 & 1075.8 \\
\hline 38 & 2056 & 2282 & 1850 & 2206 & 6550 & 7639 & 8195 & 9637 & 899.4 & 1083 \\
\hline 42 & 1902 & 2062 & 1947 & 2251 & 5934 & 6768 & 8165 & 9388 & 935.1 & 1068.5 \\
\hline 45 & 2016 & 2226 & 1691 & 2024 & 6728 & 7791 & 8248 & 9608 & 960.4 & 1122.4 \\
\hline 49 & 1735 & 1910 & 1495 & 1788 & 5738 & 6631 & 7601 & 8814 & 871.5 & 1004.5 \\
\hline 52 & 1691 & 1853 & 1509 & 1786 & 5351 & 6123 & 7346 & 8506 & 854.7 & 967.9 \\
\hline 56 & 1664 & 1821 & 1430 & 1683 & 5177 & 5896 & 6884 & 7848 & 848.8 & 952.9 \\
\hline 59 & 1404 & 1537 & 1281 & 1519 & 4379 & 4997 & 5903 & 6766 & 708.9 & 801.6 \\
\hline 63 & 1493 & 1621 & 1281 & 1499 & 4770 & 5385 & 6400 & 7257 & 795.4 & 887.9 \\
\hline 66 & 1221 & 1330 & 950 & 1130 & 4052 & 4602 & 5390 & 6120 & 680.3 & 756.7 \\
\hline 70 & 1170 & 1286 & 909 & 1085 & 3906 & 4463 & 5175 & 5895 & 674.9 & 755.1 \\
\hline 73 & 1218 & 1317 & 934 & 1095 & 4044 & 4551 & 5406 & 6090 & 723.3 & 794.1 \\
\hline 77 & 1118 & 1221 & 892 & 1063 & 3756 & 4267 & 5302 & 6038 & 648.7 & 718.2 \\
\hline 80 & 967 & 1053 & 717 & 855 & 3316 & 3747 & 4597 & 5195 & 616.5 & 681.2 \\
\hline 83 & 806 & 896 & 592 & 723 & 2998 & 3440 & 3946 & 4517 & 557.4 & 623.4 \\
\hline 87 & 636 & 668 & 436 & 500 & 2249 & 2413 & 2566 & 2745 & 432.4 & 451.7 \\
\hline 90 & 901 & 976 & 655 & 776 & 2776 & 3117 & 4330 & 4865 & 615.5 & 674.8 \\
\hline 93 & 920 & 995 & 709 & 835 & 3199 & 3585 & 4501 & 5045 & 669.3 & 729.3 \\
\hline & & & & & & & & & & \\
\hline
\end{tabular}


Table A-3. Measured VOC concentration (ppmv) in Drum 4 headspaces during Trial 1.

\begin{tabular}{|c|c|c|c|c|c|c|c|c|c|c|}
\hline \multirow[b]{2}{*}{ Day } & \multicolumn{2}{|c|}{ Methylene chloride } & \multicolumn{2}{|c|}{ Freon-113 } & \multicolumn{2}{|c|}{ 1,1,1-trichloroethane } & \multicolumn{2}{|c|}{ Carbon tetrachloride } & \multicolumn{2}{|c|}{ Trichloroethylene } \\
\hline & $\mathrm{DH}^{\mathbf{a}}$ & $\mathrm{LB}^{\mathrm{b}}$ & $\mathrm{DH}$ & LB & DH & LB & DH & LB & DH & LB \\
\hline 7 & 4489 & 5773 & 3871 & 5022 & 10271 & 14968 & 12854 & 20058 & 1208 & 2690 \\
\hline 10 & 4105 & 5129 & 3794 & 4717 & 9678 & 13276 & 11888 & 17312 & 1068 & 2129 \\
\hline 14 & 4450 & 5276 & 4348 & 5170 & 10250 & 13149 & 6830 & 9156 & 1545 & 2635 \\
\hline 17 & 2644 & 3206 & 3174 & 3875 & 6952 & 9096 & 6619 & 9057 & 1174 & 1974 \\
\hline 20 & 2809 & 3439 & 2491 & 3342 & 7615 & 9799 & 9443 & 12728 & 987.4 & 1575 \\
\hline 23 & 2373 & 2963 & 2190 & 3046 & 7562 & 10476 & 8816 & 11919 & 830.7 & 1407 \\
\hline 27 & 2164 & 2614 & 2374 & 3015 & 6435 & 8220 & 7998 & 10365 & 919.1 & 1306 \\
\hline 31 & 2118 & 2505 & 2685 & 3333 & 4400 & 5725 & 8194 & 10591 & 930 & 1277 \\
\hline 35 & 1771 & 2110 & 1597 & 2063 & 5313 & 6788 & 7017 & 9105 & 739.2 & 1071 \\
\hline 38 & 1736 & 2100 & 1528 & 2016 & 5486 & 7111 & 6810 & 8958 & 724.2 & 1030 \\
\hline 42 & 1634 & 1902 & 1635 & 2065 & 5055 & 6343 & 7024 & 8855 & 791.9 & 1024 \\
\hline 45 & 1700 & 2046 & 1380 & 1833 & 5634 & 7284 & 6957 & 9069 & 800.3 & 1077 \\
\hline 49 & 1454 & 1751 & 1194 & 1605 & 4803 & 6197 & 6396 & 8319 & 730.7 & 966.4 \\
\hline 52 & 1450 & 1707 & 1240 & 1610 & 4570 & 5751 & 6332 & 8103 & 735.5 & 935.2 \\
\hline 56 & 1404 & 1658 & 1143 & 1497 & 4322 & 5460 & 5754 & 7315 & 730.1 & 914 \\
\hline 59 & 1183 & 1414 & 1045 & 1366 & 3658 & 4665 & 4962 & 6369 & 605.1 & 770.7 \\
\hline 63 & 1259 & 1475 & 1019 & 1326 & 3990 & 4988 & 5385 & 6788 & 685.4 & 849.1 \\
\hline 66 & 1016 & 1207 & 731.9 & 987.6 & 3346 & 4256 & 4521 & 5746 & 586.9 & 726.9 \\
\hline 70 & 968 & 1158 & 686.1 & 934.7 & 3189 & 4097 & 4298 & 5485 & 579.6 & 725.6 \\
\hline 73 & 1005 & 1184 & 707 & 939.6 & 3311 & 4179 & 4536 & 5717 & 624.3 & 761 \\
\hline 77 & 929 & 1101 & 680.4 & 907.8 & 3094 & 3906 & 4421 & 5596 & 567.2 & 689.3 \\
\hline 80 & 795 & 946 & 531.1 & 719.7 & 2715 & 3441 & 3854 & 4917 & 537.4 & 657.9 \\
\hline 83 & 663 & 797 & 428.6 & 595.6 & 2451 & 3119 & 3293 & 4178 & 488.6 & 595.9 \\
\hline 87 & 693 & 831 & 448.3 & 617.2 & 2393 & 3010 & 2482 & 3136 & 489.7 & 594.8 \\
\hline 90 & 736 & 871 & 477.9 & 641.4 & 2258 & 2833 & 3596 & 4517 & 538.9 & 647.8 \\
\hline & & & & & & & & & & \\
\hline
\end{tabular}


Table A-4. Measured VOC concentration (ppmv) in Drum 1 headspaces during Trial 2.

\begin{tabular}{|c|c|c|c|c|c|c|c|c|c|c|c|c|c|c|c|}
\hline \multirow[b]{2}{*}{ Day } & \multicolumn{3}{|c|}{ Methanol } & \multicolumn{3}{|c|}{ Cyclohexane } & \multicolumn{3}{|c|}{ 1,1,1-TCA } & \multicolumn{3}{|c|}{ Toluene } & \multicolumn{3}{|c|}{ p-xylene } \\
\hline & $\mathrm{DH}^{\mathrm{a}}$ & $\mathbf{L B}^{\mathbf{b}}$ & $\mathbf{S B}^{\mathrm{c}}$ & $\mathrm{DH}$ & LB & SB & $\mathrm{DH}$ & LB & SB & DH & LB & SB & $\mathbf{D H}$ & LB & SB \\
\hline 2 & 16780 & 60723 & 93110 & 3185 & 14735 & 17128 & 2407 & 11418 & 13829 & - & - & - & 28.9 & 725 & 785 \\
\hline 7 & 47410 & 76547 & 81487 & 6195 & 15797 & 16050 & 5250 & 12452 & 12705 & 1057 & 3701 & 3753 & 92.0 & 751 & 774 \\
\hline 10 & 53145 & 76754 & 80242 & 7998 & 15847 & 16100 & 6940 & 12413 & 12651 & 2267 & 7040 & 7173 & 157.6 & 1011 & 1046 \\
\hline 13 & 53065 & 73483 & $75969^{\circ}$ & 8339 & 15245 & 15433 & 7337 & 12058 & 12235 & 2519 & 6688 & 6787 & 169.5 & 1020 & 1046 \\
\hline 16 & 50397 & 70657 & 72312 & 7899 & 14155 & 14289 & 7018 & 11393 & 11506 & 2529 & 6322 & 6402 & 188.3 & 985 & 1008 \\
\hline 21 & 51870 & 70494 & 70837 & 8590 & 14545 & 14614 & 7502 & 11608 & 11660 & 1917 & 4344 & 4379 & 241.2 & 1056 & 1075 \\
\hline 24 & 42404 & 55352 & 56007 & 7636 & 12048 & 12146 & 6800 & 9865 & 9956 & 1877 & 3758 & 3792 & 260.8 & 922 & 942 \\
\hline 28 & 42957 & 58225 & 58579 & - & 13226 & 12736 & 7024 & 10596 & 10664 & 1975 & 4056 & 4087 & 277.1 & 1035 & 1053 \\
\hline 31 & 40507 & 57627 & 57493 & 8238 & 13883 & 13927 & 7192 & 11284 & 11326 & 2067 & 4312 & 4332 & 303.0 & 1150 & 1167 \\
\hline 36 & 32588 & 47513 & 47739 & 7331 & 12654 & 12709 & 6427 & 10395 & 10436 & 1991 & 4074 & 4099 & 301.7 & 1115 & 1132 \\
\hline 41 & 30879 & 41589 & 42438 & 7661 & 12221 & 12373 & 6547 & 9843 & 9981 & 2130 & 4036 & 4072 & 336.6 & 1130 & 1154 \\
\hline 44 & 26165 & 38316 & 39729 & 7194 & 12122 & 12246 & 6080 & 9695 & 9788 & 2011 & 3966 & 4004 & 327.0 & 1146 & 1166 \\
\hline 48 & 24435 & 34539 & 34559 & 7419 & 12252 & 12250 & 6174 & 9686 & 9710 & 2100 & 4061 & 4058 & 348.3 & 1215 & 1222 \\
\hline 51 & 17992 & 28220 & 28724 & 6251 & 11146 & 11247 & 5098 & 8668 & 8753 & 1900 & 3998 & 3822 & 306.7 & 1147 & 1163 \\
\hline 57 & 14105 & 22195 & 22491 & 5791 & 10234 & 10318 & 4702 & 7990 & 8041 & 1825 & 3605 & 3628 & 298.8 & 1123 & 1140 \\
\hline 62 & 13276 & 18984 & 19242 & 5582 & 9140 & 9204 & 4645 & 7288 & 7345 & 1768 & 3168 & 3183 & 332.6 & 1003 & 1015 \\
\hline 65 & 13634 & 20244 & 20428 & 5812 & 9772 & 9822 & 4773 & 7690 & 7729 & 1886 & 3367 & 3379 & 359.8 & 1058 & 1070 \\
\hline 69 & 12627 & 18158 & 18452 & 5941 & 9717 & 9823 & 4726 & 7449 & 7540 & 1966 & 3418 & 3444 & 378.4 & 1093 & 1110 \\
\hline 77 & 8440 & 12815 & 13187 & 5481 & 9131 & 9131 & 4311 & 6949 & 6973 & 1998 & 3403 & 3205 & 395.1 & 1108 & 904 \\
\hline 80 & 9459 & 13915 & 14115 & 5695 & 9426 & 9495 & 4698 & 7523 & 7579 & 2086 & 3463 & 3479 & 441.4 & 1155 & 1167 \\
\hline 84 & 8802 & 12800 & 12028 & 5603 & 9145 & 9186 & 4592 & 7226 & 7267 & 2059 & 3362 & 3369 & 444.6 & 1126 & 1134 \\
\hline 86 & 8124 & 11855 & 12049 & 5219 & 8546 & 8610 & 4355 & 6878 & 6927 & 1965 & 3165 & 3178 & 429.5 & 1062 & 1072 \\
\hline \multicolumn{16}{|c|}{ a. Drum headspace. } \\
\hline \multicolumn{16}{|c|}{ b. Large bag headspace. } \\
\hline \multicolumn{16}{|c|}{ c. Small bag headspace. } \\
\hline
\end{tabular}


Table A-5. Measured VOC concentration (ppmv) in Drum 2 headspaces during Trial 2.

\begin{tabular}{|c|c|c|c|c|c|c|c|c|c|c|c|c|c|c|c|}
\hline \multirow[b]{2}{*}{ Day } & \multicolumn{3}{|c|}{ Methanol } & \multicolumn{3}{|c|}{ Cyclohexane } & \multicolumn{3}{|c|}{$1,1,1-\mathrm{TCA}$} & \multicolumn{3}{|c|}{ Toluene } & \multicolumn{3}{|c|}{ p-xylene } \\
\hline & $\mathrm{DH}^{\mathrm{a}}$ & $\mathbf{L B}^{\mathbf{b}}$ & $\mathrm{SB}^{\mathrm{C}}$ & DH & LB & SB & DH & LB & SB & DH & LB & SB & DH & LB & SB \\
\hline 2 & 19510 & 62370 & 94943 & 3632 & 14493 & 16806 & 2932 & 11450 & 13668 & - & - & - & 58.0 & 1033 & 1157 \\
\hline 7 & 46627 & 72916 & 76179 & 6190 & 14327 & 14714 & 5487 & 11722 & 12055 & 1055 & 3555 & 3637 & 121.1 & 888 & 924 \\
\hline 10 & 55505 & 73439 & 75474 & 8030 & 14447 & 14713 & 7301 & 11776 & 12017 & 2108 & 6490 & 6635 & 187.1 & 1119 & 1168 \\
\hline 13 & 56565 & 70600 & 72644 & 8505 & 13966 & 14162 & 7818 & 11522 & 11688 & 2311 & 6052 & 6157 & 192.0 & 1084 & 1118 \\
\hline 16 & 54242 & 67368 & 68782 & 8232 & 13134 & 13213 & 7444 & 10828 & 10906 & 2317 & 5652 & 5704 & 210.6 & 1020 & 1042 \\
\hline 21 & 55295 & 69349 & 69887 & 8715 & 13543 & 13594 & 7924 & 11280 & 11310 & 1676 & 3771 & 3799 & 249.8 & 1021 & 1035 \\
\hline 24 & 47033 & 55720 & 56501 & 7913 & 11321 & 11384 & 7361 & 9697 & 9745 & 1673 & 3263 & 3285 & 259.2 & 859 & 874 \\
\hline 28 & 49606 & 60476 & 60920 & 8571 & 12496 & 12570 & 7685 & 10462 & 10518 & 1762 & 3497 & 3523 & 277.1 & 935 & 948 \\
\hline 31 & 48767 & 60709 & 61389 & 8758 & 13056 & 13163 & 8053 & 11167 & 11246 & 1843 & 3683 & 3724 & 295.0 & 1007 & 1025 \\
\hline 36 & 40495 & 51773 & 52482 & 7811 & 11972 & 12075 & 7233 & 10341 & 10406 & 1807 & 3529 & 3560 & 295.7 & 958 & 970 \\
\hline 41 & 38985 & 45933 & 46840 & 8339 & 11689 & 11787 & 7521 & 9877 & 9975 & 2015 & 3542 & 3549 & 333.6 & 948 & 954 \\
\hline 44 & 32814 & 42992 & 43488 & 7505 & 11523 & 11689 & 6706 & 9735 & 9786 & 1833 & 3474 & 3484 & 313.0 & 944 & 952 \\
\hline 48 & 31458 & 38627 & 39089 & 7933 & 11471 & 11573 & 7043 & 9632 & 9706 & 1967 & 3531 & 3556 & 339.0 & 971 & 979 \\
\hline 51 & 24640 & 32860 & 33462 & 6645 & 10567 & 10650 & 5827 & 8768 & 8842 & 1755 & 3359 & 3371 & 287.6 & 914 & 919 \\
\hline 57 & 20090 & 26435 & 26794 & 6318 & 9709 & 9776 & 5563 & 8134 & 8184 & 1762 & 3232 & 3250 & 290.2 & 881 & 887 \\
\hline 62 & 17270 & 22241 & 22643 & 5921 & 8724 & 8774 & 5294 & 7470 & 7509 & 1725 & 2899 & 2896 & 323.7 & 801 & 794 \\
\hline 65 & 18445 & 23706 & 24141 & 6336 & 9297 & 9377 & 5603 & 7873 & 7933 & 1887 & 3095 & 3110 & 359.7 & 846 & 846 \\
\hline 69 & 17331 & 21586 & 21952 & 6543 & 9293 & 9349 & 5643 & 7670 & 7713 & 1988 & 3183 & 3179 & 377.0 & 877 & 864 \\
\hline 77 & 12220 & 15817 & 16174 & 6085 & 8786 & 8853 & 5230 & 7263 & 7321 & 2056 & 3238 & 3240 & 392.3 & 898 & 889 \\
\hline 80 & 12807 & 16664 & 17012 & 6274 & 9057 & 9121 & 5612 & 7830 & 7883 & 2169 & 3305 & 3314 & 445.9 & 941 & 938 \\
\hline 84 & 11719 & 15379 & 15707 & 5917 & 8783 & 8833 & 5266 & 7538 & 7579 & 2069 & 3226 & 3232 & 428.6 & 926 & 920 \\
\hline 86 & 11314 & 14227 & 14575 & 5900 & 8219 & 8279 & 5357 & 7189 & 7273 & 2080 & 3046 & 3056 & 437.1 & 877 & 875 \\
\hline a. & \multicolumn{15}{|c|}{ Drum headspace. } \\
\hline b. & \multicolumn{15}{|c|}{ Large bag headspace. } \\
\hline c. & \multicolumn{15}{|c|}{ Small bag headspace. } \\
\hline
\end{tabular}


Table A-6. Measured VOC concentration (ppmv) in Drum 3 headspaces during Trial 2.

\begin{tabular}{|c|c|c|c|c|c|c|c|c|c|c|c|c|c|c|c|}
\hline \multirow[b]{2}{*}{ Day } & \multicolumn{3}{|c|}{ Methanol } & \multicolumn{3}{|c|}{ Cyclohexane } & \multicolumn{3}{|c|}{$1,1,1-\mathrm{TCA}$} & \multicolumn{3}{|c|}{ Toluene } & \multicolumn{3}{|c|}{ p-xylene } \\
\hline & $\mathrm{DH}^{\mathrm{a}}$ & LB $^{\mathrm{b}}$ & $\mathrm{SB}^{\mathrm{c}}$ & $\mathrm{DH}$ & LB & SB & DH & LB & SB & $\mathrm{DH}$ & LB & SB & DH & LB & SB \\
\hline 2 & 11039 & 82861 & 97923 & 2730 & 18441 & 19583 & 2276 & 14538 & 15823 & - & - & - & 40.6 & 1447 & 1523 \\
\hline 7 & 37754 & 89641 & 91678 & 4112 & 18067 & 18296 & 4243 & 14529 & 14705 & 986 & 4680 & 4721 & 107.6 & 1231 & 1251 \\
\hline 10 & - & 87603 & 84983 & 3971 & 17677 & 16970 & 4234 & 14252 & 13916 & 1499 & 8659 & 8214 & 130.3 & 1564 & 1501 \\
\hline 13 & 40795 & 82585 & 84866 & 4542 & 16788 & 16899 & 4837 & 13672 & 13783 & 1817 & 8036 & 8087 & 147.5 & 1496 & 1516 \\
\hline 16 & 47277 & 78215 & 80121 & 5891 & 15561 & 15598 & 6213 & 12664 & 12700 & 2354 & 7537 & 7558 & 205.7 & 1432 & 1443 \\
\hline 21 & 51097 & 80260 & 81027 & 6404 & 15997 & 16019 & 6800 & 13129 & 13151 & 1771 & 5029 & 5042 & 255.2 & 1454 & 1454 \\
\hline 24 & 43360 & 65966 & 65334 & 5904 & 13725 & 13459 & 6256 & 11527 & 11335 & 1712 & 4388 & 4298 & 260.6 & 1260 & 1234 \\
\hline 28 & 43940 & 68617 & 68617 & 6267 & 14529 & 14614 & 6438 & 11990 & 12065 & 1816 & 4511 & 4324 & 281.5 & 1335 & 1335 \\
\hline 31 & 43903 & 69721 & 71077 & 6402 & 15341 & 15349 & 6793 & 12895 & 12929 & 1955 & 4763 & 4468 & 316.0 & 1462 & - \\
\hline 36 & 43978 & 56862 & 57640 & 8012 & 13774 & 13867 & 7672 & 11681 & 11743 & 2210 & 4452 & 4451 & 378.3 & 1402 & 1396 \\
\hline 41 & 37974 & 48876 & 49889 & 8226 & 13118 & 13182 & 7506 & 10926 & 10981 & 2328 & 4309 & 4254 & 417.4 & 1362 & 1362 \\
\hline 44 & 33276 & 44870 & 45795 & 7944 & 12812 & 12953 & 7190 & 10655 & 10760 & 2276 & 4192 & 4190 & 424.0 & 1362 & 1329 \\
\hline 48 & 30515 & 39634 & 40480 & 8001 & 12731 & 12764 & 7112 & 10498 & 10545 & 2384 & 4218 & 3987 & 467.7 & 1406 & - \\
\hline 51 & - & 33232 & 33786 & 6272 & 11619 & 11682 & 5492 & 9485 & 9534 & 2037 & 3925 & - & 398.1 & 1303 & 1264 \\
\hline 57 & 26093 & 26093 & 26053 & 6133 & 10621 & 10266 & - & 8714 & 8513 & - & 3718 & 3608 & - & 1252 & 1216 \\
\hline 62 & 16696 & 21460 & 21833 & 6261 & 9308 & 9366 & 5580 & 7812 & 7855 & 2127 & 3208 & 3189 & 471.9 & - & 1047 \\
\hline 65 & 17071 & 22617 & 22950 & 6564 & 9885 & 9914 & 5744 & 8184 & 8216 & 2296 & 3401 & 3384 & 517.4 & 1127 & 1102 \\
\hline 69 & 15407 & 20315 & 20633 & 6489 & 9834 & 9887 & 5528 & 7942 & 7987 & 2325 & 3449 & 3428 & 532.3 & 1148 & 1113 \\
\hline 77 & 10941 & 14414 & 14797 & 6295 & 9246 & 9323 & 5316 & 7441 & 7506 & 2493 & 3467 & 3448 & 593.3 & 1155 & 1120 \\
\hline 80 & 10869 & 15248 & 15541 & 6087 & 9472 & 9527 & 5342 & 7977 & 8020 & 2448 & 3511 & 3505 & 616.7 & 1187 & 1170 \\
\hline 84 & 10218 & 13918 & 14236 & 5872 & 9148 & 9210 & 5106 & 7632 & 7684 & 2397 & 3407 & 3403 & 618.7 & 1149 & 1134 \\
\hline 86 & 9549 & 12846 & 13166 & 5733 & 8551 & 8606 & 5090 & 7272 & 7316 & 2343 & 3210 & 3010 & 601.9 & 1080 & 1069 \\
\hline \multicolumn{16}{|c|}{ a. Drum headspace. } \\
\hline \multicolumn{16}{|c|}{ b. Large bag headspace. } \\
\hline \multicolumn{16}{|c|}{ c. Small bag headspace. } \\
\hline
\end{tabular}


Table A-7. Measured VOC concentration (ppmv) in Drum 4 headspaces during Trial 2.

\begin{tabular}{|c|c|c|c|c|c|c|c|c|c|c|c|c|c|c|c|}
\hline \multirow[b]{2}{*}{ Day } & \multicolumn{3}{|c|}{ Methanol } & \multicolumn{3}{|c|}{ Cyclohexane } & \multicolumn{3}{|c|}{ 1,1,1-TCA } & \multicolumn{3}{|c|}{ Toluene } & \multicolumn{3}{|c|}{ p-xylene } \\
\hline & $\mathrm{DH}^{\mathrm{a}}$ & LB $^{\mathbf{b}}$ & $\mathrm{SB}^{\mathrm{c}}$ & $\mathrm{DH}$ & LB & $\mathrm{SB}$ & $\mathrm{DH}$ & LB & SB & DH & LB & SB & $\mathrm{DH}$ & LB & SB \\
\hline 2 & 16983 & 93725 & 85669 & 3441 & 18662 & 18947 & 2899 & 14914 & 15066 & - & - & - & 44.8 & 1438 & 1435 \\
\hline 7 & - & 87774 & 88968 & - & 17587 & 17994 & - & 14241 & 14581 & - & 4498 & 4571 & - & 1188 & 1195 \\
\hline 10 & - & 79599 & 82842 & - & 15678 & 16254 & - & 12936 & 13436 & - & 7525 & 7800 & - & 1378 & 1428 \\
\hline 13 & 57398 & 80811 & 83924 & 5651 & 16254 & 16873 & - & 13344 & 13860 & 1871 & 7668 & 7951 & 119.3 & 1436 & 1481 \\
\hline 16 & 53888 & 76710 & 79659 & 5327 & 14920 & 15502 & 5852 & 12292 & 12776 & 1778 & 7095 & 7359 & 126.7 & 1348 & 1392 \\
\hline 21 & 58084 & 80225 & 83573 & 5863 & 15335 & 15914 & 6443 & 12774 & 13259 & 1353 & 4737 & 4920 & 156.3 & 1368 & 1419 \\
\hline 24 & 50101 & 67039 & 67850 & 5604 & 12842 & 13170 & 6148 & 10984 & 11274 & 1400 & 4000 & 4141 & 179.1 & 1181 & 1181 \\
\hline 28 & 53466 & 72359 & 75368 & 5935 & 14501 & 14501 & 6317 & 11713 & 12178 & 1476 & 4246 & 4414 & 188.7 & 1297 & 1297 \\
\hline 31 & 54215 & 75010 & 78663 & 5956 & 14641 & 15359 & 6615 & 12544 & 13156 & 1554 & 4453 & 4675 & 200.3 & 1359 & 1425 \\
\hline 36 & 46649 & 60909 & 64110 & 7448 & 12702 & 13534 & 7250 & 10958 & 11675 & 1833 & 4048 & 4321 & 259.6 & 1269 & 1355 \\
\hline 41 & 41495 & 52119 & 53702 & 7904 & 12346 & 12800 & 7357 & 10473 & 10846 & 2023 & 3993 & 4154 & 303.1 & 1255 & 1304 \\
\hline 44 & 34745 & 46855 & 48327 & 7611 & 12000 & 12400 & 6947 & 10130 & 10473 & 2007 & 3999 & 4040 & 315.0 & 1266 & 1306 \\
\hline 48 & - & 39903 & 42726 & - & 11867 & 12632 & - & 9918 & 10558 & - & - & 3524 & - & 1305 & 1389 \\
\hline 51 & 23020 & 32012 & 34050 & 6482 & 10478 & 11149 & 5766 & 8676 & 9226 & 1960 & 3555 & 3787 & 317.6 & 1183 & 1256 \\
\hline 57 & 17204 & 23332 & 25089 & 5954 & 9430 & 10039 & 5278 & 7806 & 8329 & 1952 & 3314 & 3532 & 325.6 & 1116 & 1190 \\
\hline 62 & 14736 & 19208 & 20354 & 5535 & 8397 & 8881 & 4984 & 7111 & 7519 & 1863 & 2919 & 3095 & 360.1 & 982 & 1038 \\
\hline 65 & 14486 & 19859 & 21021 & 5687 & 8855 & 9385 & 5010 & 7387 & 7839 & 1983 & 3081 & 3282 & 392.5 & 1023 & 1088 \\
\hline 69 & 13106 & 17313 & 18492 & 5706 & 8782 & 9349 & 4908 & 7149 & 7614 & 2052 & 3117 & 3332 & 411.2 & 1036 & 1108 \\
\hline 77 & 7805 & 11323 & 12171 & 5080 & 8081 & 8647 & 4309 & 6544 & 7002 & 2063 & 3086 & 3316 & 431.3 & 1026 & 1103 \\
\hline 80 & 9039 & 12147 & 12830 & 5640 & 8310 & 8799 & 4978 & 7027 & 7445 & 2255 & 3147 & 3348 & 497.8 & 1064 & 1134 \\
\hline 84 & 8329 & 10844 & 11487 & 5541 & 8037 & 8533 & 4872 & 6735 & 7148 & 2256 & 3068 & 3274 & 509.2 & 1033 & 1103 \\
\hline 86 & 7573 & 10531 & 10451 & 5179 & 7809 & 7940 & 4634 & 6678 & 6775 & 2142 & 2858 & 3077 & 487.8 & 834 & 1037 \\
\hline a. & \multicolumn{15}{|c|}{ Drum headspace. } \\
\hline b. & \multicolumn{15}{|c|}{ Large bag headspace. } \\
\hline c. & \multicolumn{15}{|c|}{ Small bag headspace. } \\
\hline
\end{tabular}




\section{Appendix B}

Computer Program to Estimate VOC Concentration Ratio in Vented Waste Drums Containing VOC Source 
B-2 
c program calculates the steady state VOC concentration in a

c lab-scale vented waste drum containing simulated waste sludge.

c-

c model assumes constant drum temperature

c-

c declaration of variables

character*21 vocid(9),ifname, ofname

integer nvoc, n,i,m

real ap(3),ad(3),xp(3),xd(3),y(9,4),temp,pHg,dch2

real amw,pm,df,b,c,atc,apc,avc

real a(4),advocair,adcvoc,test

c User provided input

c nvoc - number of VOCs in drum

c layer - number of layers of confinement

c $y(n, m)-n-t h$ VOC conc'n in m-th layer of confinement (ppmv)

c $m=1$, average concentration in headspace of each small bag

c $m=1$ or $m=2$, large bag headspace

c $m=2$ or $m=3$, drum liner headspace

c $m=3$ or $m=4$, drum beadspace

c ap(m) - permeation surface area around $m$-th layer of confinement (cm2)

c ad(m) - cross sectional area for diffusion out of $m$-th layer

c of confinement $(\mathrm{cm} 2)$

c $\operatorname{xp}(\mathrm{m})$ - thickness of permeable surface $(\mathrm{cm})$

c $x d(m)$ - length of diffusional path between layers of confinement $(\mathrm{cm})$

c dch2 - diffusion characteristic of $\mathrm{H} 2$ ( $\mathrm{mol} / \mathrm{mol}$ fraction/s)

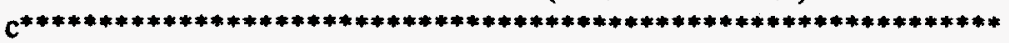

c vocid(n) - VOC identification number

c $1-\mathrm{CCl} 42$ - cyclohexane 3 - methanol $4-\mathrm{CH} 2 \mathrm{Cl} 2$

c 5 - Toluene 6-TCA 7 -TCE 8 - Freon-113 9-p-xylene

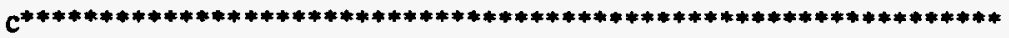

vocid $(1)=$ 'carbon tetrachloride

$\operatorname{vocid}(2)=$ 'cyclohexane

$\operatorname{vocid}(3)=$ 'methanol

vocid $(4)=$ 'methylene chloride ,

$\operatorname{vocid}(5)=$ 'toluene

$\operatorname{vocid}(6)=' 1,1,1$-trichloroethane'

$\operatorname{vocid}(7)=$ 'trichloroethylene ,

$\operatorname{vocid}(8)=$ 'Freon -113

$\operatorname{vocid}(9)=$ 'p-xylene

c--Input initial conditions from a file--..

c-

write $\left({ }^{*}, 5\right)$

5 format(1x,'Enter name of input file: ')

$\operatorname{read}\left({ }^{*},{ }^{*}\right)$ ifname

open(unit =3, file =ifname,status ='unknown')

$\operatorname{read}\left(3,{ }^{*}\right)$ test, ofname

open(unit $=2$, file $=$ ofname,status='unknown')

$\operatorname{read}\left(3,{ }^{*}\right)$ nvoc, layer

c temp - drum temperature, $\mathrm{C}$

c $\mathrm{pHg}$ - ambient pressure, $\mathrm{cm} \mathrm{Hg}$

c njc - counter $\left(1=\right.$ actual $D^{*}$, voc; $2=$ estimated $D^{*}$,voc 
c $\mathrm{n}-$ VOC identification number

$\operatorname{read}(3, *)(\operatorname{ap}(m), \operatorname{ad}(m), x p(m), x d(m), m=1$, layer-1)

$\operatorname{read}\left(3,{ }^{*}\right) \mathrm{dch} 2$,temp,pHg,njc

do $30 \mathrm{i}=1$, nvoc

$\operatorname{read}\left(3,{ }^{*}\right) \mathrm{n}, \mathrm{y}(\mathrm{n}$, layer $)$

c Computation of concentrations

call vprop(n,amw,pm,df,b,c,atc,apc,avc,adcvoc)

$c a(x)=\operatorname{alpha}(x)$ or abeta $(x)$

do $26 \mathrm{l}=1$, layer-1

if(1.le.(layer-2))then

c calculates term to estimate permeation rate from polymer bag call alpha(pm,ap(l),xp(l),temp,pHg,a(l),b,c)

else

c calculates term to estimate diffusion rate out of drum liner call beta(df,ad(l),xd(l),a(l),temp,pHg) end if

26 continue

c accounts for presence of two small bags

if(layer.eq.4) $\mathrm{a}(1)=2 .{ }^{*} \mathrm{a}(1)$

c estimate VOC diffusion characteristic if njc $=2$

if(njc.eq.2)then

call dvocair(apc,atc,amw,advocair)

call dcvoc(avc,advocair,dch2,adcroc)

else

end if

call conc(layer,a,adevoc,y,n,pHg,temp,c0)

30 continue

call output(layer,y,vocid,ap,ad,xp,xd,pHg,temp,dch2,test)

end

c

$c^{* * * * *}$ Subroutine assigns values to each volatile's properties *****

subroutine vprop(n,amw,pm,df,b,c,atc,apc,avc,dvoc)

real amw,pm,df,b,c,atc,apc,avc

integer $\mathbf{n}$

real $\mathrm{mw}(9), \mathrm{p}(9), \mathrm{d}(9), \mathrm{vpb}(9)$

real vpc(9), ,c(9),pc(9),vc(9),dv(9)

$c$ mw(i) - molecular weight of compound $i$

c $\mathrm{p}(\mathrm{i})$ - VOC i permeability across polye at $25 \mathrm{C}, \mathrm{cm} 3 \mathrm{~cm} / \mathrm{cm} 2 \mathrm{~s} \mathrm{~cm} \mathrm{Hg}$

c d(i) - diffusion of VOC $i$ in air at $25 \mathrm{C}(\mathrm{cm} 2 / \mathrm{sec})$

c vpb(i) - Antoine equation coefficient, B, for $i$-th component

$c$ vpc(i) - Antoine equation coefficient, $C(K)$, for $i-$ th component

c tc(i) - critical temperature for $\mathrm{i}$-th component $(\mathrm{K})$

c pc(i) - critical pressure for i-th component (atm)

c vc(i) - critical volume for i-th component ( $\mathrm{cm} 3 / \mathrm{mol})$

c dv(i) - VOC diffusion characteristic across NFT-020 filter vent, mol/s

c amw,pm,df,b,c,atc,apc,avc correspond to properties

c of designated VOC each time through the loop

c

c 1 = carbon tetrachloride

$\mathrm{mw}(1)=153.82$

$\mathrm{p}(1)=161 . \mathrm{e}-10$

$\mathrm{d}(1)=0.0828$

$\mathrm{vpb}(1)=1242.43$ 
$\operatorname{vpc}(1)=-43.15$

$\operatorname{tc}(1)=556.4$

$\mathrm{pc}(1)=45.0$

$\operatorname{vc}(1)=276$.

$d v(1)=3.0 e-7$

c 2 = cyclohexane

$\mathrm{mw}(2)=84.1$

$\mathrm{p}(2)=12.4 \mathrm{e}-10$

$\mathrm{d}(2)=0.0750$

$\mathrm{vpb}(2)=1203.526$

$\operatorname{vpc}(2)=-50.287$

$\operatorname{tc}(2)=553.4$

$\mathrm{pc}(2)=40.2$

$\operatorname{vc}(2)=308$.

$d v(2)=4.4 e-7$

c 3 = methanol

$\mathrm{mw}(3)=32.0$

$\mathrm{p}(3)=135 . \mathrm{e}-10$

$\mathrm{d}(3)=0.152$

$\mathrm{vpb}(3)=1473.11$

$\operatorname{vpc}(3)=-43.15$

$\operatorname{tc}(3)=512.6$

$\mathrm{pc}(3)=79.9$

$\mathrm{vc}(3)=118$.

$\mathrm{dv}(3)=6.05 \mathrm{e}-7$

c 4 = methylene chloride

$\operatorname{mw}(4)=84.9$

$\mathrm{p}(4)=244 . \mathrm{e}-10$

$\mathrm{d}(4)=0.104$

$\mathrm{vpb}(4)=1325.9$

$\operatorname{vpc}(4)=-20.55$

$\operatorname{tc}(4)=510$.

$\mathrm{pc}(4)=60$.

$v c(4)=193$.

$\mathrm{dv}(4)=4.4 \mathrm{e}-7$

c 5 = toluene

$\mathrm{mw}(5)=92.1$

$\mathrm{p}(5)=668 . \mathrm{e}-10$

$\mathrm{d}(5)=0.0849$

$\operatorname{vpb}(5)=1343.943$

$\operatorname{vpc}(5)=-53.773$

$\operatorname{tc}(5)=591.7$

$\mathrm{pc}(5)=40.6$

$v c(5)=316$.

$\operatorname{dv}(5)=3.7 \mathrm{e}-7$

c $6=\mathrm{TCA}$

$\operatorname{mw}(6)=133.4$

$\mathrm{p}(6)=83 . \mathrm{c}-10$

$d(6)=0.0794$

$\operatorname{vpb}(6)=2136.6$

$\operatorname{vpc}(6)=29.65$

$\operatorname{tc}(6)=545$.

$\mathrm{pc}(6)=42.4$

$\mathrm{vc}(6)=281$.

$d v(6)=4.0 \mathrm{e}-7$ 


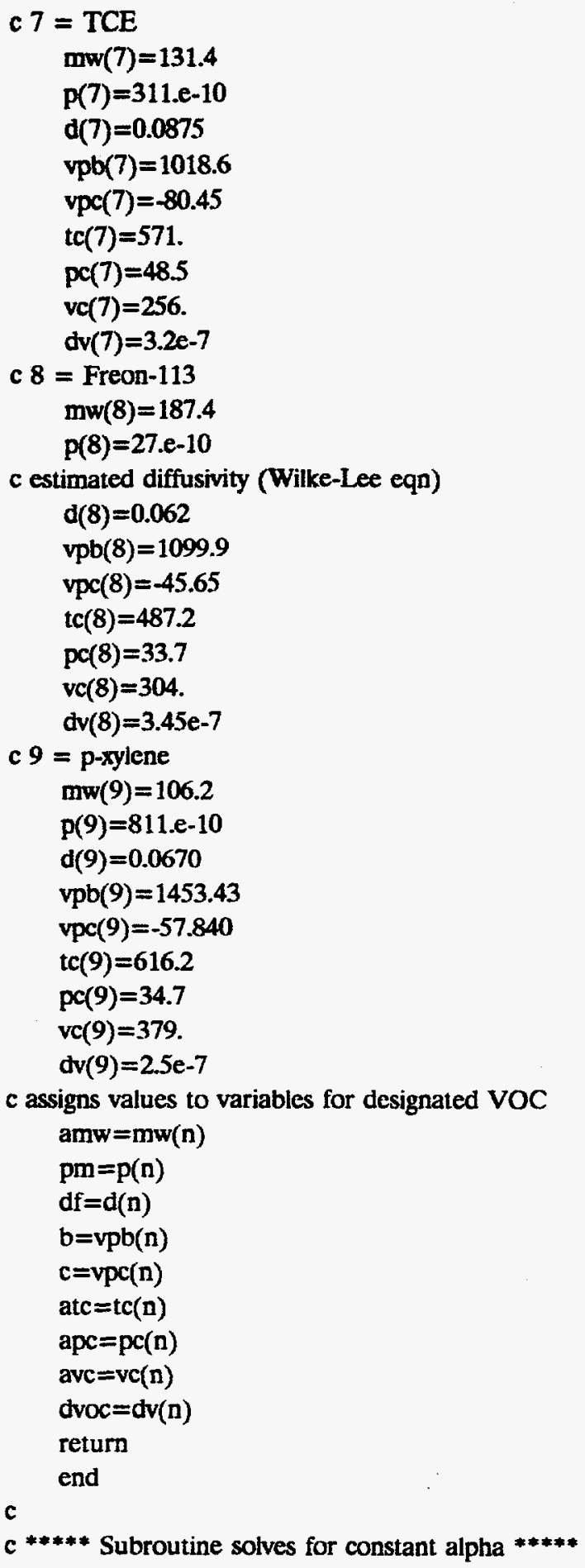

subroutine alpha(pm,ap,xp,temp,pHg,aalpha,b,c)

c Correction of permeability coefficient for drum temperature.

c Assume temperature inside poly bags and drum liner are same

c for polyethylene: $\log \mathrm{Pf}=\mathrm{K}-0.22 \mathrm{c0}$

c $\quad \mathrm{K}=\mathrm{c1}-\mathrm{c} 2 \mathrm{~T}, \mathrm{~T}(\mathrm{~K})$

c $\quad c 0, c 1, c 2=$ constants; $\quad c 2=3700$

c for liquids: $\quad P=P f / P v a p(s a t ' d)$

c Therefore $(\mathrm{P} 1 / \mathrm{P} 2)=[\mathrm{Pf} / \mathrm{Pvap}$ (sat'd) $] 1 / \mathrm{Pf} / \mathrm{Pvap}(\text { sat'd) }]^{2}$

c

c Assume same ratio relationship describes temp. effect for VOC gases 
c VOC vapor pressure estimated using Antoine equation

c current permeability, diffusivity data for $25 \mathrm{C}=298.15 \mathrm{~K}$

$c$

c td - drum temperature, $K$

$t d=$ temp +273.2

c to - reference temperature, $\mathrm{K}$

to $=298.15$

c ptk - permeability coefficient at temperature td

$\mathrm{p} 1=10 .{ }^{* *}(-3700 . / \mathrm{td}+\mathrm{b} /(\mathrm{c}+\mathrm{td}))$

$\mathrm{p} 2=10 . * *(-3700 . / \mathrm{to}+\mathrm{b} /(\mathrm{c}+$ to $))$

$\mathrm{ptk}=(\mathrm{p} 1 / \mathrm{p} 2)^{*} \mathrm{pm}$

c cstp - P/T at standard temp $(273.12 \mathrm{~K})$ and pressure (1 atm $=76 \mathrm{~cm} \mathrm{Hg})$ cstp $=76 . / 273.15$

c aalpha - computed value of alpha $(\mathrm{cm} 3 / \mathrm{s})$

aalpha $=\mathrm{ptk}^{*}(\operatorname{ap} / \mathrm{xp})^{*} \mathrm{pHg} \mathrm{g}^{*}\left(\operatorname{cstp}^{*} \mathrm{td} / \mathrm{pHg}\right)$

return

end

c

c***** Subroutine solves for constant beta *****

subroutine beta(df,ad,xd,abeta,temp,pHg)

real df,dtk,td,patm

c Correction of diffusion coefficient for drum temp.

c Assume diffusivity is proportional to $\mathrm{T}^{* *} 1.823 / \mathrm{P}, \mathrm{T}(\mathrm{K}) \mathrm{P}(\mathrm{atm})$

$c$ td - drum temperature, $K$

$\mathrm{td}=\mathrm{temp}+273.2$

$c$ to - reference temperature, $\mathrm{K}$

t0 $=298.15$

c patm - atmospheric pressure (atm)

patm $=\mathrm{pHg} / 76.0$

$\mathrm{dtk}=\mathrm{df}^{*}(1 . / \mathrm{patm})^{*}(\mathrm{td} / \mathrm{t0})^{* *} 1.823$

abeta $=\mathrm{dtk} * \mathrm{ad} / \mathrm{xd}$

return

end

$c^{* * * * *}$ Subroutine calculates the ratio of Dvoc-air/DH2-Air ***** subroutine dvocair(apc,atc,amw,advocair)

real apc,atc,amw,advocair,mwair,mwh2

c mwair, mwh2 - molecular weights of air, $\mathrm{H} 2(\mathrm{~g} / \mathrm{mol})$

$\operatorname{mwh} 2=2$.

mwair $=29$.

c pch2, tch2 are critical temperature $(\mathrm{K})$ and pressure (atm) of $\mathrm{H} 2$

$\operatorname{tch} 2=33.3$

pch2 $=12.8$

$\mathrm{c}$ variables used for intermediate calculations start with a $\mathrm{r}$

$\mathrm{rpc}=(\mathrm{apc} / \mathrm{pch} 2)^{* *} 0.3333$

rtc $=(\text { atc/tch } 2)^{* *}(-0.495)$

$\mathrm{rmw}=((1 . / \mathrm{mwair}+1 . / \mathrm{amw}) /(1 . / \mathrm{mwair}+1 . / \mathrm{mwh} 2))^{* *} 0.5$

c advocair - Dvoc-air/DH2-air (dimensionless)

advocair $=\mathrm{rpc}^{*} \mathrm{rtc}^{*} \mathrm{rmw}$

return

end

$c^{* * * * *}$ Subroutine calculates voc diffusion characteristic *****

subroutine devoc(avc,advocair,dch2,adcvoc)

real gamma,avc,advocair,dch2,rvc,vch2,adcvoc 
c gamma is a parameter indicating the distribution of pore

c sizes in the filter (see EDF RWMC-643).

c Value was determined based on experimental results. gamma $=1.2$

c vch2 is the critical volume of $\mathrm{H} 2(\mathrm{~m} 3 / \mathrm{kmol})$ $\mathrm{vch} 2=65$.

c adcvoc - voc diffusion characteristic, $\mathrm{D}^{*} \mathrm{voc}$, (mol/mol fraction/s) rvc $=(\text { vch } 2 / \text { avc })^{* *} 0.333$

adcvoc $=$ gamma ${ }^{*} \mathrm{rvc}^{*}$ advocair ${ }^{*} \mathrm{dch} 2$

return

end

c ***** Subroutine calculates concentrations *****

c -....Equations used before manipulation-_-_-_._-

c $Q 1=($ alpha + beta $) 1 *(c 2-c 1)$

c $Q 2=[($ alpha + beta $) 2 *($ c3-c2 $)]$

c $\mathrm{Q} 3=[($ alpha + beta $) 3 *(\mathrm{c} 4-\mathrm{c} 3)]$

c $\mathrm{Q} 4=-\left[\left(\mathrm{D}^{*}\right)^{*} \mathrm{y} 4\right]$

c Due to quasi steady-state assumption, $\mathrm{Q} 1=\mathrm{Q} 2=\mathrm{Q} 3=\mathrm{Q} 4=\mathrm{Q}$

c- -

subroutine conc(l,a,adcvoc,y,n,pHg,temp,co)

real a(4),adcvoc,y(9,4),q,yy(9,4),pHg,temp

real patm,co,ro,td

integer $\mathrm{n}, \mathrm{k}$

c Converts concentration in drum headspace from $\mathrm{ppmv}$ to $\mathrm{mol} / \mathrm{cm} 3$

c y has units ppmv (mole fraction)

$c$ yy has units mol/cm3 (mole concentration)

c patm - atmospheric pressure (atm)

patm $=\mathrm{pHg} / 6.0$

$c$ td - drum temperature (K)

td $=$ temp +273.15

c ro - gas constant $(\mathrm{cm} 3 \mathrm{~atm} / \mathrm{mol} \mathrm{K})$ ro $=82.06$

c co - initial gas concentration in each layer of confinement $(\mathrm{mol} / \mathrm{cm} 3)$

$\mathrm{co}=\mathrm{patm} /\left(\mathrm{ro}^{*} \mathrm{td}\right)$

$\mathrm{yy}(\mathrm{n}, \mathrm{l})=\mathrm{y}(\mathrm{n}, 1) * \mathrm{co}^{*} 1 . \mathrm{e}-6$

$q=-\operatorname{adcroc} * y(n, l)^{*} 1 . e-6$

$c$ * Computes actual concentrations *

$\mathrm{yy}(\mathrm{n}, 1-1)=\mathrm{yy}(\mathrm{n}, 1)-\mathrm{q} / \mathrm{a}(1-1)$

yy $(n, 1-2)=y y(n, 1-1)-q / a(1-2)$

if(l.eq.4)yy(n,1)=yy(n,2)-q/(2.*a(1))

c Converts predicted concentrations in mol/cm 3 to $\mathrm{ppm}$

do $130 \mathrm{k}=1,1$

$$
\mathrm{y}(\mathrm{n}, \mathrm{k})=\mathrm{yy}(\mathrm{n}, \mathrm{k}) / \mathrm{co}^{*} 1 . e+6
$$

130 continue

end

$c^{* * * * *}$ subroutine prints output to file ***** subroutine output(ly,y,vocid,ap,ad,xp,xd,pHg,temp,dch2,test)

real $y(9,4), a p(3), \operatorname{ad}(3), x p(3), x d(3)$, temp,pHg,test,dch2

character*21 vocid(9)

integer $\mathbf{n}$

write $(2,150)$ test

150 format('Trial 'f5.2)

write $\left(2,{ }^{*}\right)^{\prime}$ ' 
write $(2,152)$

152 format('Model parameters:')

write $(2,154)$

154 format(19x,'ap(cm2)',9x,'ad(cm2)',8x,'xp(cm)',9x,'xd(cm)')

write $(2,156)$

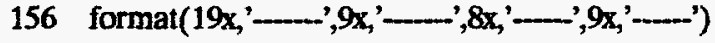

if(ly.eq.4)then

write (2,158)ap(ly-3),ad(ly-3),xp(ly-3),xd(ly-3)

158 format('2 small bags',7x,f6.0,10x,f4.2,11x,f4.2,11x,f5.2)

else

end if

write $(2,160) \mathrm{ap}(\mathrm{ly}-2), \mathrm{ad}(\mathrm{ly}-2), \mathrm{xp}(\mathrm{ly}-2), \mathrm{xd}(\mathrm{ly}-2)$

160 format('Large bag',10x,f6.0,10x,f4.2,11x,f4.2,11x,f5.2)

write (2,162)ap(ly-1),ad(ly-1),xp(ly-1),xd(ly-1)

162 format('Drum liner',9x,f6.0,10x,f4.2,11x,f4.2,11x, f5.2)

write $\left(2,{ }^{*}\right)^{\prime}$ '

write $\left(2,{ }^{*}\right)^{\prime}$ predicted VOC concentrations (ppmv) in headspace of:'

if(ly.eq.4)then

write $(2,164)$

164 format('Compound',15x,'Drum *',3x,'Drum Liner',2x,'Large Bag',

\# 2x,'Small bags',4x,'DH/SB')

write $(2,166)$

166 format('--')

else

write $(2,264)$

264 format('Compound',15x,'Drum*',3x,'Drum Liner',2x,'Large Bag', \# 4x,'DH/LB')

write $(2,266)$

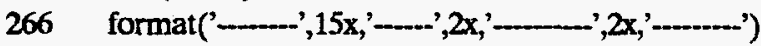

end if

do $200 \mathrm{n}=1,9$

if(y(n,ly).eq.0)goto 200

ratio $=y(n, l y) / y(n, 1)$

if(ly.eq.4)then

write $(2,168)$ vocid(n),y(n,4),y(n,3),y(n,2),y(n,1),ratio

168 format(a21,2x,f6.1,4x,f6.1,5x,f6.1,5x,f6.1,7x,f5.3)

else

write $(2,268)$ vocid(n),y(n,3),y(n,2),y(n,1),ratio

268 format(a21,2x,f6.1,4x,f6.1,5x,f6.1,7x,f5.3)

end if

200 continue

write $(2, *)^{\prime}$,

write $(2,)^{* *}$ Reference concentration'

write $(2, *)$, '

write $(2,170)$ temp

170 format('Drum temperature (C):',2x,f4.1)

write $(2,172) \mathrm{pHg}$

172 format('Ambient pressure (cm Hg):',2x,f4,1)

write $(2,174)$ dch 2

174 format('Hydrogen diffusion characteristic across filter $(\mathrm{mol} / \mathrm{mol} \mathrm{fr}$ \#action/s):',e12.5)

return

end 